\title{
Environmental effects on growth, reproduction, and life-history traits of loggerhead turtles
}

Article in Ecological Modelling · September 2017

DOI: 10.1016/j.ecolmodel.2017.07.001

CITATIONS

13

5 authors, including:

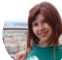

Nina Marn

Ruđer Bošković Institute

16 PUBLICATIONS 103 CITATIONS

SEE PROFILE

Tarzan Legović

Ruđer Bošković Institute

66 PUBLICATIONS 1,126 CITATIONS

SEE PROFILE

Some of the authors of this publication are also working on these related projects:

Epidemic dynamics with consideration of vaccination behavior View project

Project The AmP project: comparing species on the basis of parameter values View project
READS

337

Marko Jusup

Tokyo Institute of Technology

61 PUBLICATIONS 1,085 CITATIONS

SEE PROFILE

Tin Klanjscek

University of Zagreb

53 PUBLICATIONS 846 CITATIONS

SEE PROFILE 


\title{
Environmental effects on growth, reproduction, and life-history traits of loggerhead turtles
}

\author{
Nina Marn ${ }^{\mathrm{a}, *}$, Marko Jusup ${ }^{\mathrm{b}}$, Tarzan Legovića ${ }^{\mathrm{a}}$, S.A.L.M. Kooijman ${ }^{\mathrm{c}}$, Tin \\ Klanjšček ${ }^{\mathrm{a}}$ \\ ${ }^{a}$ Rudjer Bošković Institute \\ Bijenička cesta 54, HR-10002 Zagreb, Croatia \\ ${ }^{b}$ Center of Mathematics for Social Creativity, Hokkaido University \\ 12-7 Kita Ward, Sapporo 060-0812, Japan \\ ${ }^{c}$ Vrije Universiteit Amsterdam \\ De Boelelaan 1105, 1081 HV Amsterdam, Netherlands
}

\begin{abstract}
Understanding the relationship between the environmental conditions and life-history traits (such as growth, reproduction, and size at specific life stages) is important for understanding the population dynamics of a species and for constructing adaptable, relevant, and efficient conservation measures. For the endangered loggerhead turtle, characterizing effects of environmental conditions on the life-history traits is complicated by this species' longevity, global distribution, and migratory way of life. Two significant environmental factors - temperature and available food - often account for most of observed intra-population variability in growth and reproduction rates, suggesting that those two factors determine the biological responses of an individual. Adopting this hypothesis, we simulate a range of the two environmental factors to quantify effects of changes in temperature and food availability on an individual's physiology (energy investment into processes such as growth, maturation, and reproduction) and the resulting life-history traits. To represent an individual, we use a previously developed mechanistic dynamic energy budget (DEB) model for loggerhead turtles. DEB models rely on one of the empirically best validated general ecological theories, which captures rules of energy acquisition and utilization. We found that the ultimate size (length and mass) is primarily affected by food availability, whereas growth
\end{abstract}

*nina.marn@gmail.com 
and maturation are primarily affected by temperature whilst also showing positive correlation with available food. Reproduction increases with both food availability and temperature because food availability determines energy investment into egg production, and temperature affects the rate of related processes (such as vitellogenesis). Length at puberty varies between simulated scenarios by only a small proportion, suggesting that inter-individual variability plays a larger role for length at puberty than the environmental factors do.

Keywords: Loggerhead turtle, Environmental effects, Life history, Mechanistic model, Conservation, Marine ecology, Climate change

\section{Introduction}

Inter-individual and between-population differences in growth, maturation, and reproduction of loggerhead turtles (Caretta caretta) obstruct design of general conservation measures applicable to all regional management units and/or populations of this species [1]. Like other marine turtles, loggerheads are extremely vulnerable to natural and anthropogenic pressures due to temperature-dependent sex determination (TSD), long period required to reach puberty and reproduce, migratory way of life, and global distribution encompassing terrestrial habitats (beaches), open seas, and coastal waters $[2,3,4,5]$. In addition to the conditions present on land (e.g., predators, nest infestations, nest overheating or inundation, pressures related to tourism), the abiotic and biotic conditions in the marine environment also greatly affect the development (growth and maturation) and survival of individuals, thus determining the success of conservation measures.

Food availability and temperature could be the major determinants of an individual's growth rate and, because faster growth might increase chances of turtle's survival [6], also the major determinants of the individual's survival. Even though the variability in the observed growth rates of loggerhead turtles has been partially attributed to inter-individual variability within $[7,8]$ or between $[9,10]$ populations, most often differences in growth rates have been either partially $[9,8,10]$ or mostly $[11,12,13,14]$ attributed to the differences in experienced temperature and food abundance. Loggerhead turtles are a migratory species, and both males and females had been observed to follow certain types of temperature and food fronts [15], and/or exhibit fidelity to specific feeding areas $[16,17]$. Growth can be up to $30 \%$ faster in a neritic 
habitat ([18] as cited in [19]). As neritic habitats are characterized by food of higher energy content and higher temperatures [19], the higher growth rate in a neritic habitat further supports the thesis that food and temperature are the chief determinants of loggerhead turtle growth.

Reproduction is the other individual-based biological process that is extremely important for resilience and survival of a species [20]. A direct correlation between growth rates and reproduction output has already been suggested [21, 14], but not quantified. Different habitats, characterized by food and temperature, have been linked to drastically different adult sizes and different reproduction patterns, with the environmental factors hypothesized to be the major causes of the variability $[22,2,23,19,24]$. The length of the remigration interval (period between two nesting seasons) has been found to correlate with the average sea surface temperature (SST) [25], similarly as the periods between two clutch depositions within a single nesting season $[26,27,28]$. Large scale environmental fluctuations, such as the North Atlantic Oscillation and the El Nino Southern Oscillation have also been shown to account for a large part of nesting variability [29, 30, 31].

Climate change, in addition to strongly affecting nesting and breeding sites (e.g., via changes in sea and sand temperature or in nesting beach areas susceptible to inundation) and potentially changing the spatial distribution of loggerhead turtles $[3,5]$, will also affect temperature and/or food availability in oceanic and coastal feeding sites of loggerhead turtles [3, 32], thus affecting growth, reproduction, and other biological processes. Effects that global climate change might have on loggerhead turtles have received increased attention in the last decade (e.g., [33, 2], see also [3, 5] for a review). Slow-acting threats such as the climate change are, however, hard to study on a short time scale for which data is available [34], especially when trying to understand the balance between beneficial and detrimental effects caused by the same change. For example, higher SST might be beneficial by triggering an earlier nesting season with an increase of hatchling survival [28] and shorter internesting intervals [26], but also detrmimental by causing some populations of loggerhead turtles to decline due to changes in resource availability [2]; understanding the combined effect is much more complicated than understanding each effect alone. The omnivorous loggerhead turtles feeding on various invertebrates are considered more resilient to changes in resource availability compared to specialized species such as leatherback, hawksbill, or herbivorous green turtles [2,3], but a trophic mismatch is possible, especially for oceanic life stages of loggerhead turtles [3]. 
Furthermore, mechanisms by which changes in food availability and temperature independently affect the biological processes are extremely hard to study empirically for a long lived, large, and widely distributed species such as the loggerhead turtle. Hence, these mechanisms have only partially been explored and remain largely unquantified. Mechanistic deterministic models can generally help, especially with quantifying the consequences of a wide range of environmental conditions and with predicting the biological responses of individuals to environmental change [2,34], but have not been used to investigate effects of environmental factors on loggerhead turtles.

Adopting the hypothesis that food availability and temperature are the two key environmental factors that determine the physiological processes and life history traits of loggerhead turtles, we use a previously constructed and calibrated mechanistic model of the North Atlantic loggerhead turtle [35] to decipher the effects of the two environmental factors (food availability and temperature) on biological traits of the loggerhead turtle.

In the following sections we first explain how we mapped the environmental factors to the energy budget and physiological processes (such as growth, maturation, and reproduction) of the loggerhead turtle. Second, we visualize the results of our simulations in terms of several key life-history traits: age and length at puberty, seasonal and cumulative reproduction output of mature turtles, and ultimate size (length and mass of fully grown adults). We conclude with the summary of our most important results and implications thereof, including the implications of climate change.

\section{Methods}

Physiological processes of loggerhead turtles were simulated using a mechanistic model based on Dynamic Energy Budget (DEB) theory [36] - a metabolic theory successfully applied to almost 700 animals from all major taxa (see the Add-my-pet collection [37]), and used in over 500 publications (see http://www .bio.vu.nl/thb/deb/DEB_papers.pdf for a complete list). Model setup is explained in Subsection 2.1. The predicted properties were analyzed in the context of currently experienced environmental conditions, and compared to the properties reported in literature. In addition to investigating life history traits, we also analyzed scaling of body mass with carapace length, and scaling of reproduction output with carapace length for a reduced set of environments. Schematic presentation of the study setup can be found in Figure 1. To reduce variability that could be introduced 
by differences between populations, only one, the North Atlantic population, was studied (see also [38]). Environmental conditions were simulated as a range of deviations from current food availability (estimated from available data [35]) and a range of ecologically realistic average sea surface temperatures (from Hawkes et al. [39]). Exact environmental simulation setup is explained in Subsection 2.2.

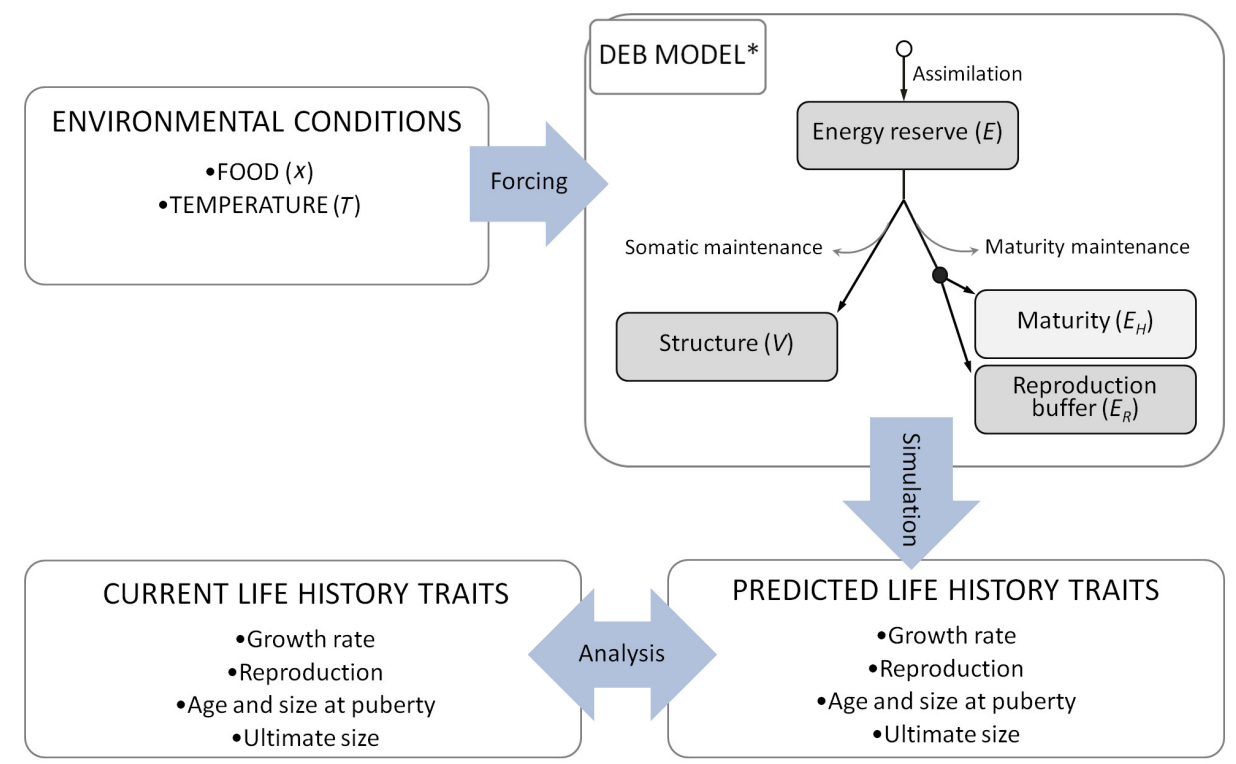

Figure 1: Schematic presentation of the study setup. Main environmental forcing factors are (scaled) food density $(x)$ and temperature $(T)$ which vary between simulations, but are kept constant throughout each simulation of the turtle's life-cycle. Simulated and analyzed traits included growth rates, reproduction rates, seasonal and cumulative reproduction output, size (length and mass) and age at puberty, size of fully grown adults, as well as the relationships of length and mass, and length and seasonal reproduction output. * Scheme of the standard DEB model.The rectangles are the main state variables; circles denote metabolic switches: empty circle - onset of feeding, full circle - onset of reproduction; see subsection 2.1 for a brief overview. Detailed description of the model and its parameterization for the North Atlantic loggerhead turtle can be found in Marn et al. [35]. The main parameters of the model (from Marn et al. [35]) are listed in Table 1. 


\subsection{Mapping the environmental factors to the energy budget and biology of} loggerhead turtles

Biology of loggerhead turtles was studied by following physiological processes (such as growth, maturation, and reproduction), and life-history traits (growth rates, age and size at puberty, size of fully grown adults - ultimate size, relationships between length and mass, and length and reproduction output). We predicted the processes and the traits at a given food level and temperature using a mechanistic model [35] based on a general metabolic theory (Dynamic Energy Budget - DEB theory, see [40, 41, 42, 43, 44, 45] for in-depth discussion). Relevant DEB-related terms and concepts are briefly presented (following the length-energy framework in Kooijman [36]) in the next four paragraphs. Detailed description of the standard DEB model for the North Atlantic loggerhead turtle, including the model's parameterization and validation, can be found in [35].

The North Atlantic loggerhead turtle can be described well by the simplest (standard) form of DEB models [35]. The standard DEB model recognizes three life stages of an individual - embryo (does not feed or reproduce), juvenile (feeds but does not reproduce), and adult (feeds and reproduces). Transitions (birth and puberty, respectively) between life stages occur when the amount of energy, measured in Joules, cumulatively invested into increase in complexity (maturation), reaches a certain threshold. The variable tracking the investment is called maturity, and its thresholds - maturity at birth and maturity at puberty - are expressed in Joules $(\mathrm{J})$. Within the DEB-framework, an individual (turtle) is defined by three state variables that change with time: In addition to 'maturity' (symbol $E_{H}$, unit J), the standard DEB model tracks 'structure' (symbol $V$, unit $\mathrm{cm}^{3}$ ) and 'energy reserve' (symbol E, unit $\mathrm{J}$ )(Figure 1). When food is abundant, all three state variables increase with time until puberty, after which maturation ceases and the energy is directed into reproduction. The energy committed to reproduction is tracked by an auxiliary state variable, 'reproduction buffer' (symbol $E_{R}$, unit J); the energy accumulated in the buffer is utilized for egg production prior to nesting. To calculate the reproduction output, we assumed that nesting occurs every two years [46] if there is enough energy stored in the reproduction buffer to produce at least one egg (210 kJ [47]).

Structure, energy reserve (and the reproduction buffer in the adult stage) contribute to the biomass of a turtle. Structure and energy reserve were converted to length and mass of the individual using standard auxiliary equations $[36,35]$. Age at puberty corresponds to the age at which the 'maturity 
at puberty' threshold is reached [36], which is earlier than the actual first reproductive event.

Processes and parameters. Energy reserve in DEB models serves as a buffer between the individual and the environment during short-term environmental fluctuations. Adults and juveniles assimilate energy from the environment into the reserves, from which energy can be utilized for maintenance, growth, maturation, and reproduction even during food shortages. Energy utilization and allocation among processes will depend on parameter values (see Lika et al. [48] for an example of parameterization). The main parameters of the model, estimated for the loggerhead turtle by Marn et al. [35] are listed in Table 1.

DEB theory relies on a $\kappa$-rule $[36,49,50]$, which guarantees that maturation and growth do not compete. Structure and maturity both require maintenance (named somatic and maturity maintenance, respectively). Somatic maintenance has absolute priority: energy investment into growth, maturation, and reproduction is possible only after maintenance has been paid. Note that energy reserve and the reproduction buffer do not require maintenance in DEB models.

Assimilation of energy from the environment into the turtle, i.e., the amount of energy per unit of time that will be transformed into energy reserve [36] is determined by the assimilation flux, $\dot{p}_{A}$ :

$$
\dot{p}_{A}=\left\{\dot{p}_{A m}\right\} V^{2 / 3} \frac{x}{x+1},
$$

where $V$ is structural volume, $\left\{\dot{p}_{A m}\right\}$ is the maximum surface area-specific assimilation rate, and $x$ is food density scaled by the (species- and food-type specific) half-saturation constant, $K$. Note that $V^{2 / 3}$ represents surface area of structure. The fraction appearing in Equation 1 is often denoted $f$ and called the scaled functional response:

$$
f=\frac{x}{x+1} .
$$

Quantity $f$ is a saturating function of food density which has a minimal value of zero when no food is available, and a maximal value of 1 when food is abundant. The scaled functional response can also be defined as a fraction of the maximum feeding rate of an individual of the given size [36, 51], depending not only on the environment but also on the physiology of an individual. Scaled functional response for North Atlantic loggerhead turtles, 
Table 1: Standard DEB model primary and auxiliary parameters for North Atlantic loggerhead turtle population used in simulations. Detailed description of the model pertaining to the North Atlantic loggerhead turtle (including data used for parameter estimation and discussion regarding the validity, implications, and applicability of the model) can be found in Ref. [35]. Rate parameters are listed at the reference temperature $T_{\text {ref }}=273 \mathrm{~K}$. Notation: square brackets, [ ], indicate parameters normalized to structural volume, and curly brackets, \{\} , indicate parameters normalized to structural surface area (see www.bio.vu.nl/thb/research/bib/Kooy2010_n.pdf for details on notation).

\begin{tabular}{llll}
\hline Parameter & Symbol & Value & Unit \\
\hline \hline Maximum specific assimilation rate & $\left\{\dot{p}_{A m}\right\}$ & 906.1 & $\mathrm{~J} \mathrm{~d}^{-1} \mathrm{~cm}^{-2}$ \\
Digestion efficiency (of food to reserve) & $\kappa_{X}$ & 0.8 & - \\
Energy conductance & $\dot{v}$ & 0.0708 & $\mathrm{~cm} \mathrm{~d}^{-1}$ \\
Allocation fraction to soma & $\kappa$ & 0.6481 & - \\
Reproduction efficiency & $\kappa_{R}$ & 0.95 & - \\
Somatic maintenance & {$\left[\dot{p}_{M}\right]$} & 13.25 & $\mathrm{~J} \mathrm{~d}^{-1} \mathrm{~cm}^{-3}$ \\
Maturity maintenance rate coefficient & $\dot{k}_{J}$ & 0.002 & $1 \mathrm{~d} \mathrm{~d}^{-1}$ \\
Specific cost for structure & {$\left[E_{G}\right]$} & 7847 & $\mathrm{~J} \mathrm{~cm}^{-3}$ \\
Maturity at birth & $E_{H}^{b}$ & $3.809 \mathrm{e}+04$ & $\mathrm{~J}$ \\
Maturity at puberty & $E_{H}^{p}$ & $8.73 \mathrm{e}+007$ & $\mathrm{~J}$ \\
Arrhenius temperature & $T_{A}$ & 7000 & $\mathrm{~K}$ \\
Shape coefficient & $\delta_{\mathrm{SCL}}$ & 0.3744 & - \\
Specific densities & $d_{V}, d_{E}$ & 0.28 & $\mathrm{~g} \mathrm{~cm}^{-3}$ \\
\hline \hline
\end{tabular}

Other primary and auxiliary parameters: Maximum searching rate,

$\left\{\dot{F}_{m}\right\}=6.5 \mathrm{ld}^{-1} \mathrm{~cm}^{-2}$; Defaecation efficiency (of food to faeces), $\kappa_{P}=0.1$; Reproduction efficiency, $\kappa_{R}=0$, 95; Maturity maintenance rate coefficient, $\dot{k}_{J}=0.002 \mathrm{~d}^{-1}$; Weibull aging acceleration, $\dot{h}_{a}=1.85 e-0101 \mathrm{~d}^{-2}$; Gompertz stress coefficient, $s_{G}=0.0001$

marked hereafter as $f_{C}$, was estimated as $f_{C}=0.81$ [35]; the corresponding $x_{C}$ can then be back-calculated using Equation 2.

In subsequent analyses, $K$ and $\left\{\dot{p}_{A m}\right\}$ were assumed constant throughout the turtle life cycle, meaning that only changes in food quantity were taken into account, while food quality was assumed to be constant. This was a simplification. The effects of food quality could be accounted for by modifying $\left\{\dot{p}_{A m}\right\}$ by a dimensionless food quality parameter (see Section 2 in [52]); food of better quality would result in a higher assimilation flow (see Equation 1). The effect on the assimilation would, however, be difficult to differentiate from the effect of changes in food density (Equation 1) because both effects act to reduce assimilation flux, i.e., reduce $f$. In other words, 
predictions for an environment with lower food quality would be qualitatively indistinguishable to predictions for an environment with lower food quantity presented herein.

The other environmental factor that will strongly influence the energy budget and biology of ectothermic organisms such as sea turtles is temperature. DEB theory argues that changes in temperature equally affect all metabolic rates (see Section 1.2 in Kooijman [36]). Because the body temperature of juvenile, sub-adult and moderately active adult chelonid turtles corresponds to the surrounding water temperature [53] (as would be expected for an ectotherm), we used the sea surface temperature as a proxy for body temperature. The average temperature experienced by the loggerhead turtles was set to $21.8^{\circ} \mathrm{C}[33,54]\left(T_{C}=294.95 \mathrm{~K}\right)$. All rates and parameters of DEB models are generally expressed at a reference temperature of $20^{\circ} \mathrm{C}$ $\left(T_{\text {ref }}=293.15 \mathrm{~K}\right)[36]$; for consistency, we adhere to the principle. Correction for the effect of temperature is done using the Arrhenius equation (from Equation 1.2 in [36]):

$$
C(T)=\exp \left(\frac{T_{A}}{T_{\text {ref }}}-\frac{T_{A}}{T}\right)
$$

where $C(T)$ is the correction factor for a certain temperature $T$, and $T_{A}$ is the Arrhenius temperature equal to $7000 \mathrm{~K}$ for loggerhead turtles [35]. For example, the assimilation flux (Equation 1) at temperature $T$ is: $\dot{p}_{A}(T)=$ $\dot{p}_{A}\left(T_{\text {ref }}\right) * C(T)$.

\subsection{Simulating the environment}

Simulations were performed over a $31 \times 31$ grid of different environmental conditions using 15 equidistant values higher and 15 equidistant values lower than the current values for scaled food density $\left(x_{C}\right)$ and temperature $\left(T_{C}\right)$. In total, 961 environments were thus simulated as possible combinations of food density and temperature. During each simulation, which lasted a turtle's lifetime of 65 years, the environment was assumed to be constant.

Values for scaled food density $(x)$ ranged from a decrease of $75 \%$ to an increase of $200 \%$ relative to the current scaled food density $\left(0.25 x_{C}\right.$ to $\left.3 x_{C}\right)$. Equation 2 was employed to turn each simulated food density into the scaled functional response $(f)$ (Figure 2.2, left panel), which was then used as a proxy for food availability. Explored scaled food densities ranged from those resulting in a very high scaled functional response $(f>0.9)$ to those identified 
in the preliminary analysis as unable to sustain reproduction $(f \leq 0.6)$. We assumed that values outside this range are rarely (if ever) present in nature: scaled functional responses close to the maximum are reached only at extremely high food densities (for example, $f=0.999$ for loggerhead turtles is reached at a scaled food density 22 times higher than the currently estimated density, $x_{C}$ ), and values lower than the simulated ones would imply extinction due to lack of reproduction.

Values for temperature ranged from $287.15 \mathrm{~K}$ to $303.15 \mathrm{~K}\left(14^{\circ} \mathrm{C}\right.$ to $30^{\circ} \mathrm{C}$ $[39,54])$. Metabolic rates were corrected for each simulated temperature using Equation 3 (Figure 2.2, right panel). The loggerhead turtles in the North Atlantic rarely experience sea temperatures outside this range, even during winter [39], with adults being more efficient than juveniles in keeping their body temperature close to optimal values [55, 54].

In addition, a subset of 30 environments was set up to disentangle the roles of food availability and temperature, and to present results in a more straightforward manner. To emphasize the role of food availability, 15 environments were set up with equidistant scaled food densities (15 values for scaled food density ranging from $0.25 x_{C}$ to $\left.3 x_{C}\right)$, but with a single temperature $\left(T=T_{C}\right)$. Similarly, to emphasize the role of temperature, 15 environments were set up with equidistant temperatures ( 15 values ranging from $287.15 \mathrm{~K}$ to $303.15 \mathrm{~K}$ ), but with a single food density $\left(x=x_{C}\right)$.

Each environment was simulated for a duration of 65 years, corresponding to the age of the oldest recorded loggerhead turtle [56]. Simulations presented here therefore implicitly assume that loggerhead turtles keep their food intake and body temperature relatively stable through out their life. This simplification is justified in the sense that the turtles (i) modulate food intake by adapting searching activities to satisfy their energy needs and (ii) stabilize experienced temperature by following thermoclines [54]. Habitat shifts during a life-time (such as those from a pelagic to a neritic environment [57]) are therefore not explicitly modeled. Although beyond the scope of this study, the model in principle allows exploring changes in the average conditions at some point in the life cycle. All simulations were performed in Matlab R2011b. Modified "EVHR" scripts by L. Pecquerie ${ }^{1}$ were used with permission.

\footnotetext{
${ }^{1}$ IRD Brest, laure.pecquerie@ird.fr
} 

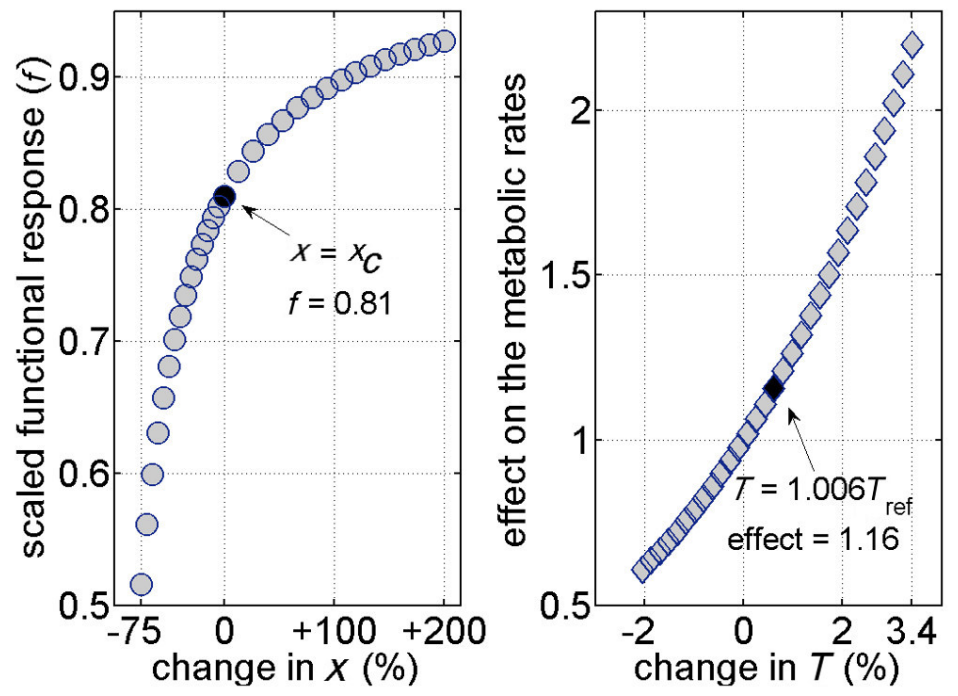

Figure 2: Simulated environmental factors: scaled food density ( $x$, left panel) and temperature $(T$, right panel) on the x-axes, plotted with the corresponding scaled functional response ( $f$, Equation 2) and the effect on metabolic rates (Equation 3) on the y-axes (see Subsection 2.1 for details). Scaled food density is expressed here as a decrease ( $\leq-$ $75 \%)$ or an increase $(\geq+200 \%)$ of the current scaled food density $\left(x_{C}\right)$. Temperature is expressed here as a decrease $(\leq-2 \%)$ or an increase $(\geq+3.4 \%)$ of the reference temperature $\left(T_{\text {ref }}=293.15 \mathrm{~K}=20^{\circ} \mathrm{C}\right)$ - the temperature at which all DEB rate parameters are generally given [36]. The left panel of the figure illustrates why a relatively large decrease in (scaled) food density will have a much stronger effect than an equally large increase in (scaled) food density ( $f$ is a saturating function of $x$ ). Biological processes and rates (such as maintenance, assimilation, and growth) are, in contrast, exponential functions of temperature: for example, a $2 \%$ decrease in temperature will have a somewhat weaker effect ( $40 \%$ slower rate relative to the rate at $T_{\text {ref }}$ ) than an analogous increase (resulting in a $60 \%$ faster rate relative to the rate at $\left.T_{\text {ref }}\right)$. Conditions used as current for the North Atlantic populations $\left(x_{C}\right.$ and $\left.T_{C}\right)$ are marked with full symbols. 


\section{Results}

\subsection{Selected life-history traits}

The patterns that emerge while predicting the selected life-history traits (age and length at puberty, length and mass of fully grown adults, and seasonal and cumulative reproduction output of fully grown adults) in the simulated 31x31 environmental grid of food density and temperature reveal which of the two environmental characteristics (food availability or temperature) has the predominant effect on a specific life-history trait (Figure 3). For example, values for a trait predominantly affected by food availability (plotted on the x-axis) will vary from left to right, but remain constant from top to bottom. Analogously, if trait values vary from top to bottom, but not from left to right, temperature (plotted on the y-axis) has the predominant effect on the trait. A diagonal pattern suggests that the trait is simultaneously affected by both environmental conditions.

Food availability strongly affects length of a fully grown adult (ultimate length), which varied between 61 and $110 \mathrm{~cm}$ straight carapace length (SCL) for the set of simulated environments (Figure 3.A, and Figure 4.A). Temperature, by contrast, does not affect the ultimate length an individual can reach ([42, 36, 45], see also Figure 4.A, and Figure 5, top left panel). However, because growth is slower at lower temperature (Figure 5, top left panel), an individual might die before reaching its ultimate length. This is mirrored in our results: the duration of simulations corresponds to the maximum life span, so the realized ultimate length is smaller at lower temperatures.

Length at puberty generally exhibits limited variation with food availability: predicted values range from $76.6 \mathrm{~cm}$ SCL to $77.2 \mathrm{~cm} \mathrm{SCL}$, and are not affected by temperature (Tables C.4 and C.3 in Appendix C). A similar effect of food availability (but not temperature) on mass at puberty is observed, with a relatively narrow range of predicted values (Tables C.4 and C.3 in Appendix C).

A predominant effect of food availability, but also a relatively strong effect of temperature, are predicted for mass of fully grown adults (ultimate mass) (Figure 3.B, Figure 4.C and D). Predictions for ultimate body mass in the environments differing in food availability have a wider range than those for the environments differing in temperature (compare Table C.3, column 7 and Table C.4, column 4 in Appendix C). This was expected because food availability affects the maximal reachable ultimate length (and body mass scales approximately with length cubed [58]), whereas the temperature gen- 

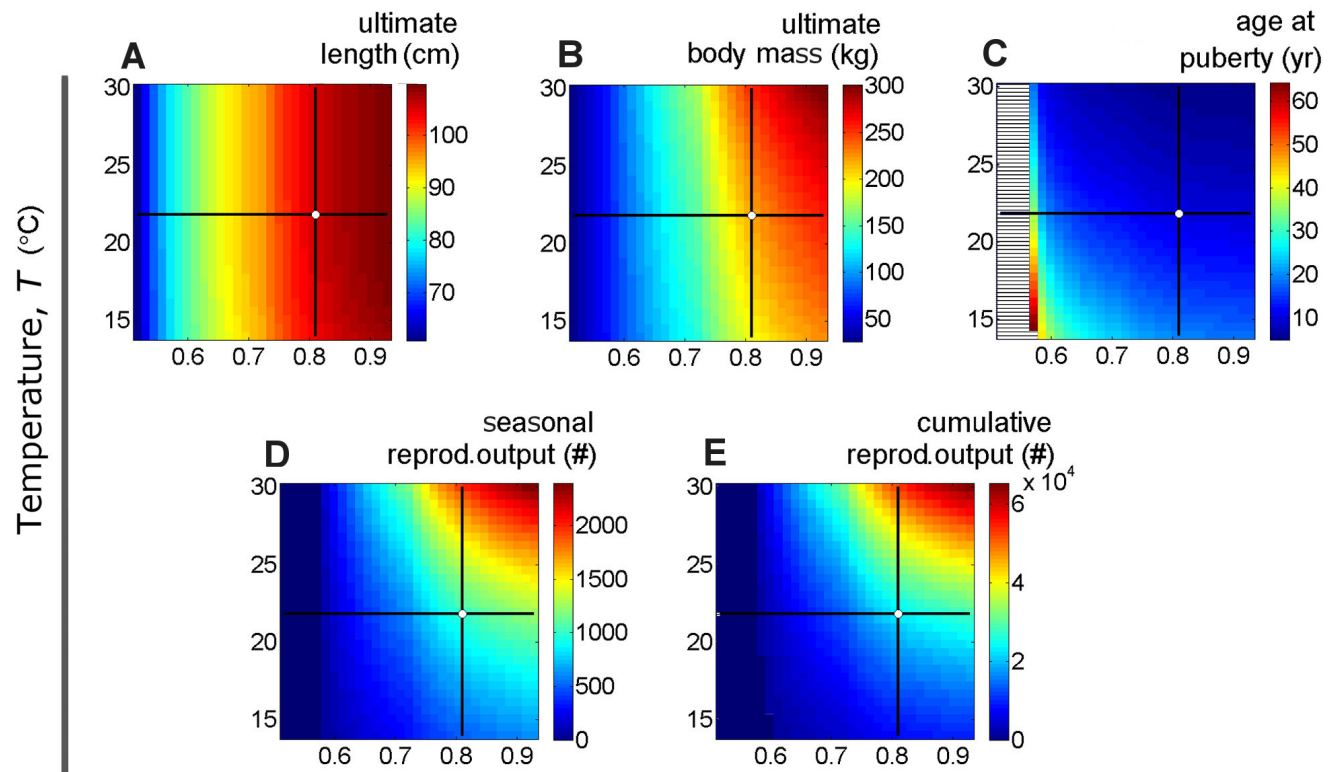

Food availability, $f$

Figure 3: The effects of the environment on the selected life history traits of North Atlantic loggerhead turtles. Food availability (scaled functional response, $f$ ) is on the x-axis and temperature ( $T$, denoted in degrees Celsius) is on the y-axis. Values of the traits are represented by colors; see color map on the right of each panel for corresponding absolute values. Panels: $[\mathrm{A}, \mathrm{B}, \mathrm{D}, \mathrm{E}]$ traits of fully grown adults: A. length (cm SCL); B. body mass $(\mathrm{kg})$; D. seasonal reproductive output (number of eggs in a nesting season, \#); E.cumulative reproductive output (number of eggs in a lifetime, \#). Panel C: age at puberty (year). At low food availability $(f<0.6)$, puberty cannot be reached, hence a part of panel $\mathrm{C}$ contains no data (marked with horizontal bars). The corresponding parts in panels D and $\mathrm{E}$ have values of zero indicating no reproduction. Two thick lines in the panels denote the subsets of the environments: at the horizontal lines $\left(T=T_{C}=21.8^{\circ} \mathrm{C}\right)$ environments differ in food availability, and at vertical lines $\left(f=f_{C}=0.81\right)$ environments differ in temperature. The white circle at the lines' intersection marks the environmental conditions currently experienced by the North Atlantic loggerhead turtles [39, 54, 35]. (Simulation setup explained in Section 2.2) 
erally does not affect the ultimate length (but can slow down growth, see above). To explain why temperature, somewhat counter-intuitively, has a relatively large affect on ultimate body mass, predictions for the body mass need to be analyzed in the context of predictions for the reproduction output which are affected by temperature. Namely, mass of the reproduction buffer was included when calculating the ultimate body mass: the model predicts that mass of the reproduction buffer is between $8 \%$ and $25 \%$ of the ultimate body mass at different environmental temperatures (under the assumption of biannual reproduction). The proportion of ultimate body mass attributable to a reproduction buffer is between $2 \%$ and $17 \%$ in environments differing in food availability. A favorable environment (high food availability, high temperature) therefore affects ultimate body mass via two mechanisms: (i) by allowing individuals to grow to a larger size, and (ii) by providing more energy for reproduction, which results also in larger mass of the reproduction buffer.

Both simulated environmental factors strongly affect age at puberty, and (seasonal and cumulative) reproduction output of fully grown adults (Figure 3.C, D, and E, see also 4.E to H). Predictions for age at puberty range from 5.5 years to $>60$ years (Figure 3.C). For environments characterized with food availabilities $f \leq 0.6$, the model predicted that puberty cannot be reached, resulting also in no reproduction. In a subset of environments differing only in food availability (with temperature $21.8^{\circ} \mathrm{C}$ ) the predictions for age at puberty range from 9.72 years to 28.71 years (mean value of $13.35 \mathrm{yr}$ ) (Table C.3, column 3 in Appendix C), and in a subset of environments differing only in temperature (with $f=0.81$ ) the predictions range from 6.49 years to 23.52 years (mean value of $13.31 \mathrm{yr}$ ) (Table C.4, column 2 in Appendix C). In the range between $18^{\circ} \mathrm{C}$ and $26^{\circ} \mathrm{C}$, a temperature difference of $1^{\circ} \mathrm{C}$ results in approximately a 1-year difference in age at puberty. Outside of this range, age at puberty changes at an approximate rate of 0.5 years for every degree centigrade between $26^{\circ} \mathrm{C}$ and $30^{\circ} \mathrm{C}$ and 2 years for every degree centigrade between $14^{\circ} \mathrm{C}$ and $18^{\circ} \mathrm{C}$, suggesting a strong negative effect of temperatures lower than $18^{\circ} \mathrm{C}$ on maturation.

Seasonal and cumulative reproduction output both have a range of an order of magnitude in a subset of environments that differ in temperature, and of two orders of magnitude in a subset of environments that differ in food availability (last two columns in Tables C.3 and Table C.4 in Appendix C, respectively, see also Figure 4.G and H). The reproduction buffer can be a substantial part of adult sea turtle's body mass [21], but it is unlikely that 

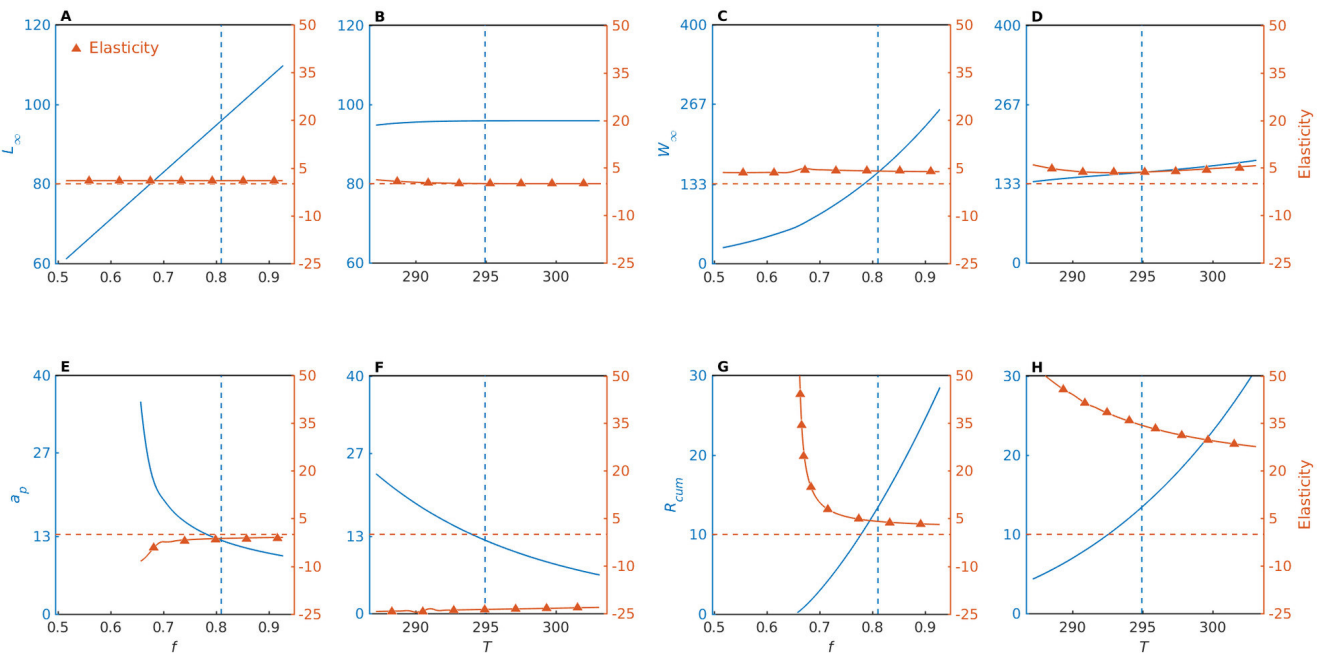

Figure 4: Elasticity analysis, showing the relative change of a life history trait (on the left $\mathrm{y}$-axis), if the forcing variable (on the x-axis) changes by $1 \%$. The horizontal dashed line marks elasticity equal to zero, which means that the life-history trait is independent of the forcing variable. If elasticity is a non-zero constant, then the life-history traits depends on the forcing variable, but the relationship is linear. Larger elasticity implies larger sensitivity of the life-history trait to $f$ or $T$ (on the $\mathrm{x}$-axis). The elasticity of the reproductive output has the most non-linear relationship, especially in the range of $f$ and $T$ values where puberty is barely reachable.

it would reach the $43 \mathrm{~kg}$ predicted for warm environments with high food availability. Rather than accumulating such a large reproductive buffer, the turtle is more likely to reproduce annually if conditions are so favorable.

\subsection{Growth and reproduction rates}

Predicted growth curves in Figure 5 (top two panels) show faster growth at higher food availability and temperature with one notable difference: increased food availability positively affects the size of fully grown adults (Figure 5, top left panel), whereas the temperature does not. At lower temperatures, however, it takes more time to become a fully grown individual (Figure 5, top right panel).

Predicted reproductive output increases with both food availability and temperature (Figure 5, bottom two panels, see also Figure 4.G and H), with the range of the predicted values larger in the subset of environments differing in food availability (Figure 5, bottom left panel). Interestingly, the model 
predicts a very similar seasonal reproduction output for lower temperature and higher food availability as it does for higher temperature and lower food availability, highlighting a synergistic effect of the two environmental factors on reproduction. For example, a fully grown adult turtle has an almost identical reproduction output in an environment characterized by temperature of $21.8^{\circ} \mathrm{C}$ and food availability $f \approx 0.87$, as it does in an environment with temperature of $30^{\circ} \mathrm{C}$ and food availability $f=0.81$. Similarly, a fully grown adult turtle experiencing a temperature of $21.8^{\circ} \mathrm{C}$ and food availability $f \approx 0.7$, has an almost identical reproduction output as if experiencing a temperature of $14^{\circ} \mathrm{C}$ and food availability $f=0.81$.

\subsection{Scaling of body mass and seasonal (biannual) reproduction output with carapace length}

The relationship between straight carapace length (SCL) and body mass does not markedly differ between the simulated environments (Figure 6, top two panels), but subtle differences are present. Because food availability has a strong effect on the maximal reachable length (Subsections 3.1 and 3.2 ), the length-mass curve is extended in environments with higher food availability (Figure 6, top left panel). The temperature does not have such an effect on the ultimate body size (Subsections 3.1 and 3.2), so the lengthmass relationship stays the same in all environments (Figure 6, top right panel). The scatter of the predicted body mass values is somewhat larger in the range of SCL values $\geq 77 \mathrm{~cm}$ SCL (corresponding to length at puberty, Subsection 3.1). The scatter can be explained by fluctuations (in mass) of the reproduction buffer (Figure 5, bottom two panels).

The seasonal biannual reproduction output and carapace length scale linearly in all simulated environments, but with markedly different patterns depending on whether food availability or temperature differ between the simulations (Figure 6, bottom two panels). When environments differ in food availability, the seasonal reproduction is seemingly completely positively related to the carapace length (Figure 6 bottom left panel), suggesting that individuals of the same length will have the same seasonal reproduction output regardless of the experienced food availability. By contrast, when environments differ in temperature, individuals of a given carapace length produce more eggs in environments with higher temperatures (Figure 6, bottom right panel). This implies that, when food is abundant, the available time (duration of the nesting season, duration of the inter-nesting period, etc.) becomes the limiting factor. 

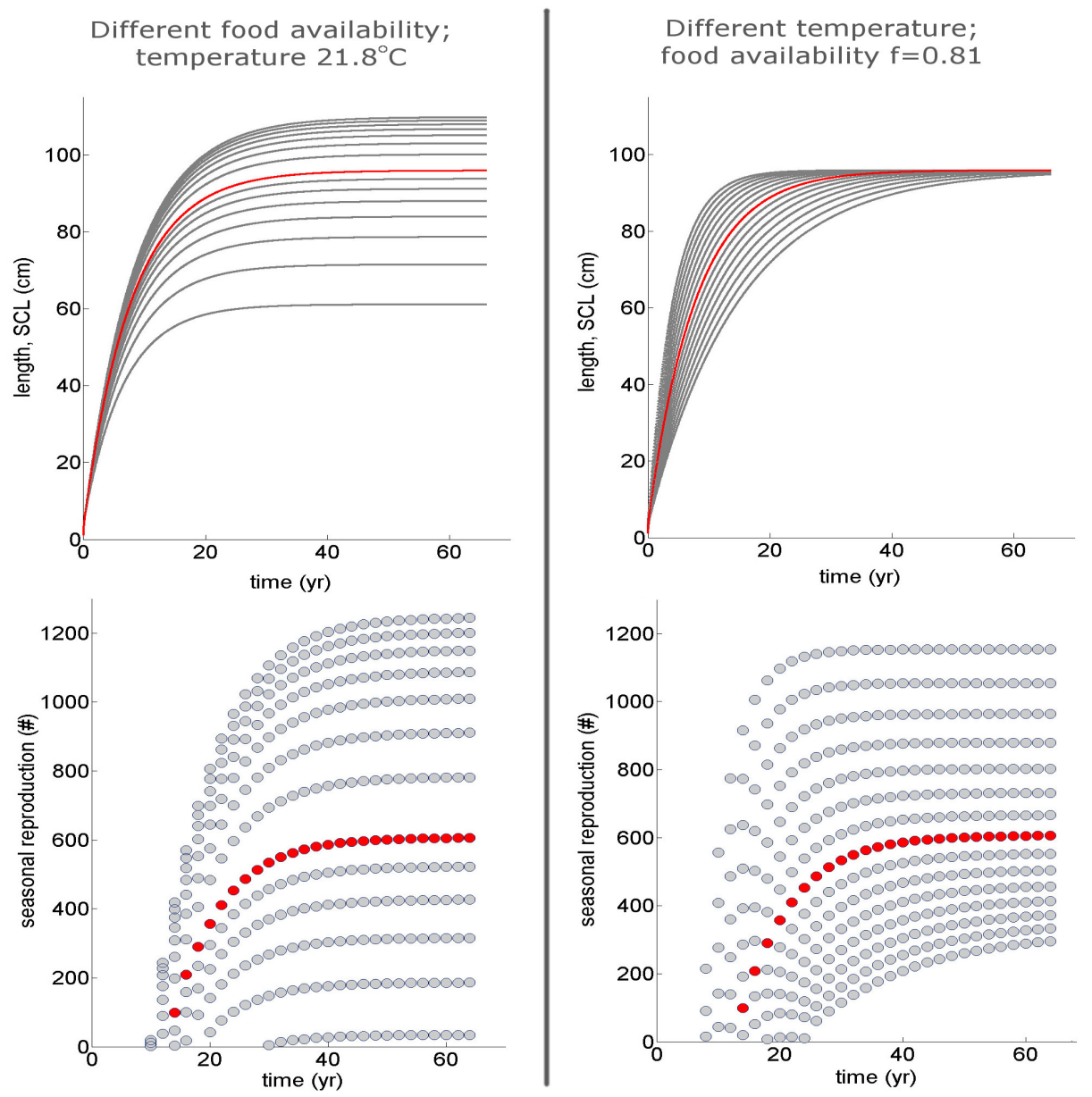

Figure 5: Growth curves (top two panels) and biannual reproduction curves (bottom two panels) predicted for a subset of environments differing in food availability or temperature. Left panels: Food availability ranging from $0.516 \leq f \leq 0.927$ at $T=T_{C}=294.95 \mathrm{~K}$ $\left(21.8^{\circ} \mathrm{C}\right)$. Right panels: temperature ranging from $287.15 \mathrm{~K}\left(14^{\circ} \mathrm{C}\right)$ to $303.15 \mathrm{~K}\left(30^{\circ} \mathrm{C}\right)$, with $f=f_{C}=0.81$. Growth and reproduction at $f_{C}$ and $T_{C}$ are denoted in red. At lower food availability, loggerhead turtles reach a smaller size, which results in lower reproduction. At lower temperatures, loggerhead turtles grow slower and start reproducing later, but the ultimate length and length at puberty are not affected. 

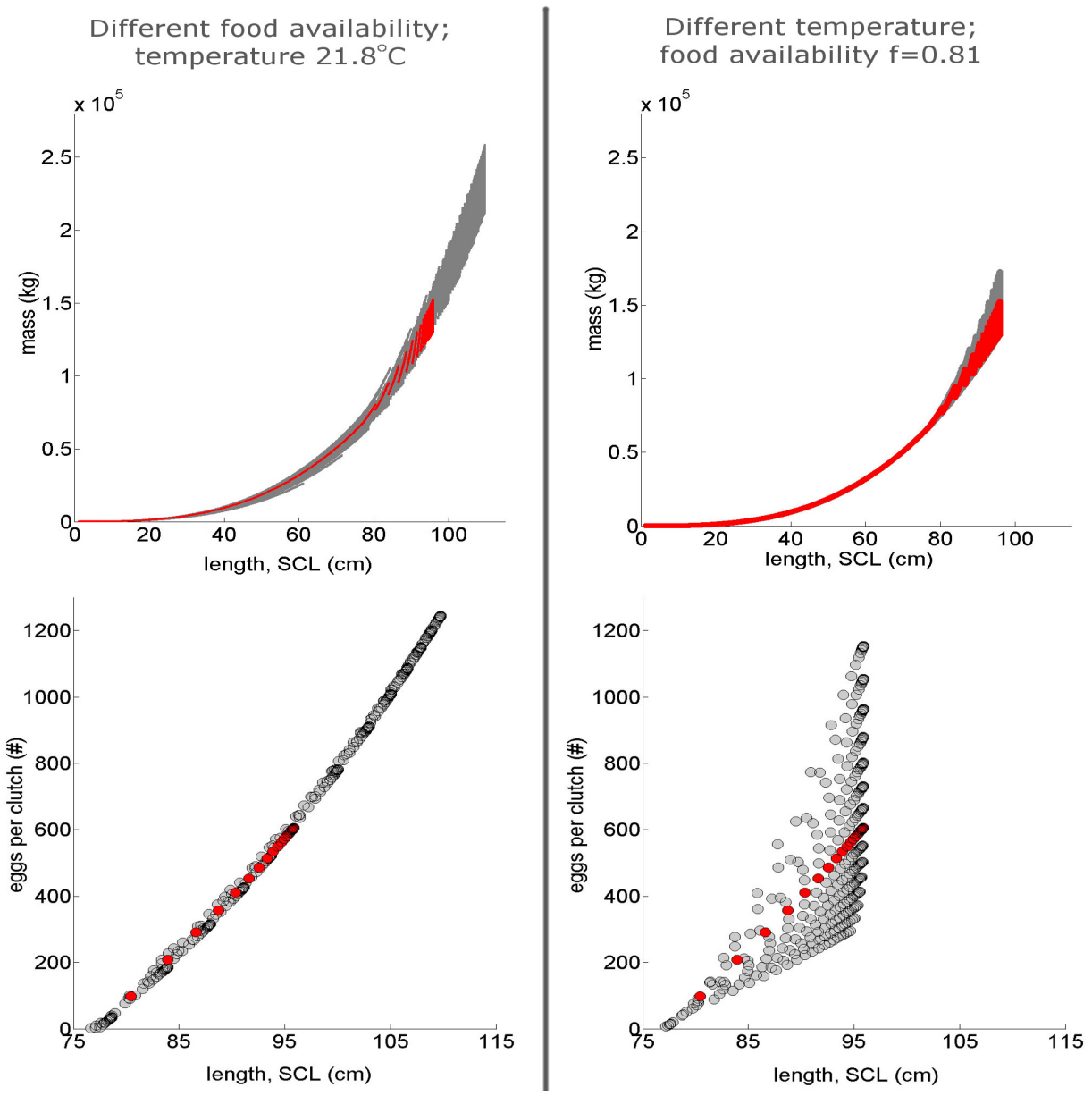

Figure 6: The relationship between carapace length and body mass (top two panels), and carapace length and seasonal (biannual) reproduction output (bottom two panels) as predicted for a subset of environments differing in food availability or temperature. Left panels: Food availability ranging from $0.516 \leq f \leq 0.927$ at $T=T_{C}=294.95 \mathrm{~K}$ $\left(21.8^{\circ} \mathrm{C}\right)$. Right panels: temperature ranging from $287.15 \mathrm{~K}\left(14^{\circ} \mathrm{C}\right)$ to $303.15 \mathrm{~K}\left(30^{\circ} \mathrm{C}\right)$, with $f=f_{C}=0.81$. The length-mass and length-reproduction relationships at $f_{C}$ and $T_{C}$ are denoted with red color. In warmer environments with more available food, turtles grow to larger sizes, and hence have larger reproduction outputs. Reproduction output of turtles with a specific carapace length is strongly affected by the simulated temperature: the reproductive output is larger at a higher temperature. 


\section{Discussion}

Processes (growth, maturation, and reproduction), as well as life history traits (ultimate size, age and size at puberty, and the reproduction output), are affected by both the environment (temperature and food availability), and the individual characteristics (physiology of a loggerhead turtle). The DEB model helps disentangle the effects of the two causes of variability by conceptually separating the effects of physiology (represented by DEB model parameter values) from the effects of the environment (food availability and temperature). By fixing the physiology, and only varying environmental conditions, our results demonstrate the extent to which two environmental factors (food availability and temperature) can affect the processes and the life history traits. Below, we put the results into the context of existing knowledge and data.

\subsection{The non-linear relationship between the two studied environmental fac-} tors and the physiology of loggerhead turtles

Defining the relationships between environmental factors and the resulting life-history traits (Subsection 2.1) was the baseline for predicting the effects of the environmental conditions on the observable biological quantities. Ranges of the simulated temperature and food availability, albeit somewhat arbitrarily chosen, are realistic: the simulated temperature range has been reported for North Atlantic loggerhead turtles [39], and the simulated food density ranges from values at which reproduction is impossible (implying extinction), and values giving functional response very close to the maximal. The non-linear relationships for the dependence of the scaled functional response on (scaled) environmental food density (a proxy for food availability, Equation 2), and of the metabolic rates on temperatures (Equation 3) were taken from the thoroughly tested DEB theory $[36,45]$.

The current food availability was estimated to be relatively high $\left(f_{C}=\right.$ 0.81 [35]), and, because food availability is a saturating function of scaled food density (Equation 2, Figure 2.2, left panel), reducing scaled food density has a much stronger effect on the predicted traits than increasing it by the same relative amount. If food availability is low to begin with, even a small further reduction of food density results in a large decrease in the scaled functional response (Figure 2.2), and a strong negative effect on the biological traits. The consequences of reduced food availability in areas where food availability is relatively low (e.g., in the Mediterranean Sea and oceanic 
habitats $[59,19])$ may, therefore, be more dramatic than in areas with high food availability.

The exponential relationship between temperature and physiological rates (Equation 3) results in a relatively large effect of a small temperature change on metabolic rates: for the range of simulated temperatures, the rates were suggested to be as much as $40 \%$ smaller and up to $120 \%$ greater than the rates at the reference temperature of $293.15 \mathrm{~K}=20^{\circ} \mathrm{C}$ (Figure 2.2, right panel). Although the change may seem drastic, it is still realistic. If we assume loggerhead turtles experience a temperature of around $20^{\circ} \mathrm{C}$ in the oceanic habitat [19], and then move to a neritic habitat characterized by $24^{\circ} \mathrm{C}$ [19], the model predicts an increase in metabolic rates by almost $40 \%$. This prediction is consistent with the noted "up to $30 \%$ faster growth" in a neritic habitat reported by Snover [18] (as cited in Ref. [19]).

\subsection{How do the predicted growth and reproduction curves compare to data?}

Growth rates generally differ between life stages and between populations (genetic stocks) of loggerhead turtles [9, 10, 14]. However, similar growth rates were also reported between individuals belonging to different populations and/or life stages $[11,13,14]$ suggesting a strong influence of extrinsic (e.g., environmental) factors. Growth estimates derived from capture-markrecapture data (e.g., $[9,11,60]$ ), growth marks on the bones (e.g., [61, 8, 62]), or length frequency analyses (e.g., $[12,63]$ ) should therefore be interpreted in the context of the environmental data, with possibly special emphasis on the conditions present during the initial part of the development $[64,65,7]$. The intertwining effect of food availability and temperature on growth curves (and thus growth rates) of identical individuals reproduced by the model (Figure 5, top two panels) highlights why a direct comparison of growth data could be misleading.

Different environmental conditions may result in practically indistinguishable growth rates. For example, in warmer environments with low food availability growth rates of sea turtles might decrease between $50 \mathrm{~cm}$ and $60 \mathrm{~cm}$ straight carapace length (SCL) (this study) because individuals approach ultimate size $[66,9,14]$. In an environment with high food availability but low temperature, our results show that growth rates might decrease around the said size range due to a decrease in temperature. The inter-dependency of growth and environmental conditions can be reconstructed with the help of a DEB model $[67,51]$ by combining, e.g., the environmental data, our mechanistic model for loggerhead turtles, and skeletochronology. 
The model can be (partially) validated by calculating the growth rates plotted in Figure 5, and comparing them with literature. For example, the model predicts that growth from $25 \mathrm{~cm}$ to $75 \mathrm{~cm} \mathrm{SCL}$ requires between 7 and 19 years (when food availability is varied at temperature of $21.8^{\circ} \mathrm{C}$ ), and between between 5 and 18 years (when temperature is varied at $f=$ 0.81 ). The low ends of the predicted ranges correspond to environments characterized by warm temperatures and high food availability; an example of such an environment could be the Southern Bahamas, where extremely fast growth was observed. Two loggerhead turtles needed just 3 to 4 years to grow from $25 \mathrm{~cm}$ to $75 \mathrm{~cm}$ SCL [11].

The average prediction in simulated environmental subsets is around 10 years to grow from $25 \mathrm{~cm}$ to $75 \mathrm{~cm} \mathrm{SCL}$. This is consistent with the observed time needed for the Florida population, Frazer and Ehrhart [68] (in Ref. [11]), for which estimates indicate 10 (von Bertalanffy model) to 16 years (logistic model) are needed to achieve the same growth. Available information for a different size span (growth from $50 \mathrm{~cm}$ to $75 \mathrm{~cm} \mathrm{SCL}$ ) is also in agreement with our results: Mendonça [9] calculated that Florida loggerheads need 5 years to grow from $50 \mathrm{~cm}$ to $75 \mathrm{~cm} \mathrm{SCL}$, whereas the average time predicted by the model for the simulated subset of the environments is around 6.5 years (between 3 and 12 years for varying food, and between 4 and 14 for varying temperature). A more elaborate report on the predicted growth rates (in $\mathrm{cm}$ $\mathrm{yr}^{-1}$ ) in the context of literature values can be found in Appendix A.

A direct comparison of the reproduction output predicted by the model and the values reported in literature is complicated by the many uncertainties that plague in situ observations of the total seasonal reproduction output (and thus also the cumulative reproductive output) of an individual female $[47,46,69]$. Examples where annual reproduction output is reported or calculated are rare, but available information corroborates our results: we predict that mass of the reproduction buffer (when reproduction is biannual) is between $2 \%$ and $25 \%$ of the ultimate mass, which is consistent with approximately $10 \%$ of the total body mass reported for annual clutch mass of marine, freshwater, and terrestrial turtles [21].

Seasonal and cumulative reproduction output of individuals in our study was positively affected by both food availability and temperature. The range of predictions was larger when environments differed in food availability than in temperature (Subsections 3.1 and 3.2). The results therefore imply that sea turtles in warmer and energy richer neritic environments [19] will have a larger reproduction output than those in an oceanic environment, but also 
that the simulated range of food availability has a stronger influence on the reproduction output than the simulated range of temperature. The reproduction output has indeed been linked to the type of habitat (oceanic vs neritic) [23], with the dichotomy between smaller adult females having a smaller reproduction output and larger adult females having a larger reproduction output explained primarily by energy available for reproduction [23].

While the link between food (energy) availability and reproduction output is straightforward, the link between temperature and reproduction reported in the literature is somewhat ambiguous: Chaloupka et al. [2] hypothesized that loggerhead turtles with a higher reproduction output experienced environments with a higher food abundance and lower temperature than the loggerheads with a lower reproduction output, suggesting that the effect of temperature on reproduction output, if present at all, is minor. Furthermore, no correlation was found between temperature at the breeding sites and reproductive output (number of clutches per nesting season) [28], but the correlation was found between reproductive output and temperature at feeding sites [70]. Loggerhead turtles spend just a fraction of their time at breeding sites where they do not feed. During this period the processes related to egg production (such as vitellogenesis) take place [71, 72].

The apparent conflict can, however, easily be resolved by following the reasoning used for the model construction. The assumption made in our model was that the energy is assimilated from the environment and invested into the reproduction buffer continuously throughout the year [36], i.e., we do not differentiate between fractions of time at feeding and breeding sites. Higher energy investment into the reproduction buffer (and thus production of more eggs) predicted by the model can be a result of two distinct factors: (i) higher food abundance in the environment (more energy available for assimilation), and (ii) warmer environment (faster assimilation of energy and production of eggs). Areas of higher temperature could be combined with higher food quality $[19,14]$, but do not need to in order to correlate with a higher reproduction output (more eggs per turtle) - such areas could affect metabolic rates just via temperature (Equation 3, Table C.4). Either scenario would result in more energy being continuously invested into the reproduction buffer, thus increasing the reproductive output. In the context of continuous investment into reproduction, the predicted positive correlation of temperature and the reproduction output complies with the "capital breeders" hypothesis, where temperature at breeding sites may affect the timing of breeding events, but not the total energy committed to breeding [33]. 
Furthermore, our results imply that increasing either temperature or food availability, in addition to increasing the reproduction output, increases the growth rate and decreases age at puberty, i.e., increases the maturation rate (Figures 3-6). This link has already been hypothesized by Iverson [21], who noted that maturation rates and annual reproduction output could be directly linked to growth rates, i.e., the rate of energy acquisition.

Predictions for maturation rates, i.e., the time required to reach puberty varied greatly between simulated environments: predicted values were between 10 years and 15 years for most of the simulated range, but also values as small as 5.5 years were predicted for environments with high food availability and high temperature, and values larger than 40 years were predicted for environments with low food availability and low temperature (Figures 3.C). Mendonça [9] estimated that loggerhead turtles needed between 10-15 years to reach puberty, but also noted that loggerhead turtles reared in captivity need 6-8 years, and loggerhead turtles in the Pacific 25-30 years to reach puberty (References in [9]). Wild loggerhead turtles in the North Atlantic might need as long as 19 years to $>35$ years to mature [18, 8, 73]. It is reasonable to assume that captive-reared loggerhead turtles experience a higher average temperature and/or fewer exposures to low temperatures, as well as a higher food availability compared to those in the wild, making model predictions in excellent agreement with observed data.

\subsection{Scaling of body mass and seasonal (biannual) reproduction output with carapace length}

The analyzed relationship of carapace length and body mass exhibited less variation across the simulated environments compared to the relationship of carapace length and seasonal reproduction output (Figure 6). Limited variation in scaling of body mass with carapace length is in agreement with the empirical finding that a single curve explains the whole size range, with a high measure of goodness of fit even when data from more populations are pooled into analysis $\left(R^{2}=0.97,[58]\right)$.

Scaling of seasonal reproduction output with carapace length should be interpreted with the assumption about biannual nesting in mind (Section 2, see also Subsection 4.4), but is nonetheless informative when analyzing the commonly reported relationship of carapace length and clutch size (e.g., in $[47,46,74])$. For example, our results imply that individuals of the same size will have a similar seasonal reproduction output regardless of the experienced 
food availability (Figure 6, bottom left panel), suggesting a positive correlation between carapace length and clutch size. However, the reproduction output of an individual of a certain length strongly varies with temperature (Figure 6, bottom right panel), suggesting that the positive correlation between carapace length and clutch size should have a large scatter. Since loggerhead turtles experience variable environmental factors, we expect to observe a positive correlation between carapace length and clutch size, with a large scatter or low goodness of fit measure; indeed, this is true $\left(R^{2}=0.30\right.$ [47], $R^{2}=0.29$ [74], see also Figure 1 in [46]).

Patterns in the scaling relationships also suggest two distinct mechanisms through which a warmer environment with more available food can result in a higher reproduction output: (i) higher food availability enables individuals to grow to a larger size, and larger size has a strong correlation to the seasonal and cumulative reproductive output; (ii) warmer temperature affects all metabolic rates (including food assimilation, energy mobilization, and chemical transformations [36]), many of which are involved in production of eggs $[71,75]$. This is consistent with the empirical finding that a higher temperature at breeding sites correlates with the shorter period between two clutch depositions within a single nesting season [26, 27, 28], probably by increasing the rate of processes related to vitellogenesis [71]. Hence, two individuals experiencing the same food availability, but exposed to different temperatures during the year, will have a different reproductive output: the individual that experienced higher temperature will have a higher reproductive output due to both having accumulated more energy for reproduction, and a faster vitellogenesis. This result implies that, at high energy accumulation rates (feeding in warm environments with abundant food), temperature at breeding sites may become the limiting factor in reproduction: higher temperature will result in a shorter period between two nest depositions within a nesting season, whereas lower temperature will require a longer nesting season.

\subsection{Model considerations}

We assumed a constant environment (characterized by constant food availability and temperature) for our simulations. Loggerhead turtles certainly do not experience the same environmental conditions during their entire life cycle, but the annual averages should not differ too much between the years. In the context of the simulation, the seasonal variation should mostly cancel out (months at higher-than-average temperature roughly canceling 
out months at lower-than-average temperature). The model in principle allows exploring fluctuations in the conditions, but the previous explorations of DEB models show that results for life history traits such as length and mass of fully grown adults would show the same patterns, and the growth and reproduction curves would include more fluctuations but would show the same general trend [36]. Including changes in the average conditions at some point in the life cycle, e.g., to mirror the ontogenetic habitat shift [57] could make an informative extension of the standard model.

We assumed biannual reproduction and did not transform the predicted seasonal reproduction output into number of clutches (nests). In the field, most often a clutch size is used as a measure of the reproduction output of females [46, 74], or nest counts in a nesting season are used for assessing the reproduction (nesting) activity of a specific population (e.g., [31]). Transforming the seasonal biannual reproductive output (predicted by the model) to the number of nests per nesting season or number of eggs per clutch is complicated by the trade-off between the number of clutches (nests) per season, eggs per clutch, internesting intervals, and remigration intervals [47, 21, 46]. Generally, loggerhead turtles that are not first-time nesters have a modal value of 4-5 nests per nesting season $[46,76,69]$, and nests with fewer than 50 eggs or more than 200 eggs are rarely observed in nature [47, 77, 78], so a seasonal reproduction output of around 100 eggs (for first time nesters) up to around 1000 eggs would be realistic. By forcing the reproduction to occur every two years if there is enough energy in the reproduction buffer even for a single egg, and not limiting the number of eggs per season (see Section 2), unrealistically small and large seasonal reproduction outputs were predicted (Figure 3.D; Tables C.3 and C.4 in Appendix C). It is more likely that those loggerhead turtles with more energy available will have shorter remigration intervals (i.e., reproduce every year), whereas those with less energy available will have longer remigration intervals (i.e., reproduce three or more years apart) [23]. The reproduction output could be constrained by a minimal and a maximal seasonal outputs, and the remigration intervals allowed to correlate with temperature [25]. It is likely that remigration intervals with a modal value of 2-3 years, yet ranging from 1 to 7 years [74] could be reproduced in such a way, and more realistic seasonal reproduction output values could be obtained. Nevertheless, we decided to implement a remigration interval of 2 years [46]. Even though this simplification occasionally resulted in predictions for a seasonal reproduction output smaller or larger than observed, the predictions for cumulative reproduction output 
were not affected. In addition, by omitting an additional layer of complexity, the interpretation of results was kept more straightforward, and comparisons between model predictions and data are still possible and informative.

Climate change is most likely to affect loggerhead turtle populations through changes of environmental conditions on breeding and nesting sites $[33,3,5]$, so the research has been focused on distribution, temperaturedependent sex determination, and/or nesting activity (e.g., [2, 3, 5]). However, conservation efforts require quantification of processes over the whole life cycle - most of which is in the marine environment, and poorly understood. This study, by focusing on environmental conditions in the marine environment, therefore provides important missing information and methodology for studying specific effects of climate change on loggerhead turtles. For example (see Appendix B), should the ongoing climate change act on the loggerhead turtles at sea just by increasing the sea temperature, our results suggest that the loggerhead turtles will grow and reproduce faster, but there will be no discernible effect on the size distribution of loggerhead turtles within a population. If, however, such a temperature increase is coupled with a decrease in food availability, loggerhead turtles will grow at at a rate as if the environment has not changed, but will grow to a smaller size. The possible increase in temperature can, therefore, mask a moderate decrease in food availability if growth rates are directly measured in the field, but the decrease in food availability will result in a different size distribution within a population due to a larger proportion of smaller individuals.

\section{Conclusion}

Mechanisms by which environmental factors (food availability and temperature) affect physiological processes are crucial for studying correlations between environmental trends or oscillations and growth rates, reproduction output, or other life history traits of sea turtles (e.g., [26, 29, 31]), as well as for using the conclusions from those studies for conservation activities. We investigated environmental effects on biology (processes and life history traits) of North Atlantic loggerhead turtles using a mechanistic model [35] based on Dynamic Energy Budget (DEB) theory [36]. Our study relies on the model developed by Marn et al. [35], which successfully reproduced the full life cycle and general ecological properties of North Atlantic loggerhead turtles. Marn et al. [35], however, focused on the energy budget of the loggerhead turtles and the implied physiological properties such as the ability to 
cope with periods of starvation, giving a secondary role to the environment.

Here, we focus on the environment characterized by average temperature and food availability experienced by North Atlantic loggerhead turtles, and the way it shapes growth rates, reproduction rates, scaling relationships, and other life-history traits of loggerhead turtles. The mechanistic model made it possible to independently study effects of the two environmental factors on the selected biological traits. By modifying only the environment, we try to generate the observed variability in the selected biological properties of North Atlantic loggerhead turtles.

The DEB framework allowed us to map food density and temperature in the environment onto the energy budget of a loggerhead turtle (Subsection 2.1) in a thermodynamically consistent and an empirically validated manner [45]. Relationships that play a critical role in the present analyses are (i) the saturating dependence of the scaled functional response (food availability, or food intake) of loggerhead turtles on food density and (ii) the exponential dependence of physiological rates on temperature.

Even though our predictions are based on the assumption that all have the same DEB parameters and only differ in state variables, the predictions successfully reproduced many patterns observed in nature (Subsections 4.2 and 4.3). For example, we predict that the scaling of body mass with carapace length will have limited scatter, while the reproductive output will exhibit a large degree of scatter, a pattern observed in nature $[47,46,58,74]$. If, however, inter-individual variability were markedly higher in real life, we would expect a high degree of scatter in body mass vs. length as well. Therefore, the assumption that individuals are almost identical, but experiencing different environments, is more consistent with the observations than the assumption that differences between individuals are the chief drivers of differences between individual performance (growth, reproduction, etc).

Satisfactory agreement between simulations and available data over a range of food availabilities and/or temperatures also corroborated the hypothesis that two environmental factors - food availability and temperature - are the major cause of variability in biological properties of loggerhead turtles within a population (Subsections 4.2 and 4.3). This conclusion may not apply when individuals of different populations (or life stages) are compared, yet the results of this study can serve as a good starting point for such comparisons (e.g., between individuals belonging to the North Atlantic and the Mediterranean populations, inhabiting markedly different habitats $[59,10])$. The size of fully grown adults was strongly affected by food availability 
(loggerhead turtles reached smaller sizes at lower food availabilities), whereas length at puberty was relatively stable within a population. Age at puberty, and (seasonal and cumulative) reproduction output were positively affected by both food availability and temperature, with an apparently stronger effect of food availability than temperature. The results suggest that, should food density or temperature decrease, loggerhead turtles would need more time to reach puberty and produce fewer eggs. Temperature had a marginal effect on the ultimate body mass, influencing the size (and mass) of the reproduction buffer: reproduction output of a turtle with a specific carapace length was higher at a higher temperature.

Growth and reproduction curves predicted for simulated environments suggested faster growth and maturation in warmer environments with higher food availability (such as neritic habitats). Even though faster growth was predicted at a higher temperature, unless more food was available, the ultimate size was the same as when temperature was lower. Higher food availability and higher temperature resulted in a lower age at puberty, and a higher reproduction output (seasonal and cumulative) of individuals. The predictions for the reproduction output differed by two orders of magnitude over the simulated range of food densities, and one order of magnitude over the range of simulated temperatures, suggesting a strong effect of both food availability and temperature on the reproduction output. On a population level, environments with higher food availability might be correlated with a higher reproduction output because individuals can grow to a larger size, and because more energy can be (continuously) invested into reproduction. Warmer environments, by contrast, might result in a higher reproduction output because of the positive effect of higher temperature on physiological rates (earlier onset of reproduction, shorter remigration and inter-nesting intervals, etc). Reduction in food availability adversely impacted all life history traits in the simulations, and food level reductions below $50 \%$ of the current (scaled) food density made reproduction impossible.

The model provides a mechanistic context that can help interpret scaling of body mass and reproduction output with carapace length. Studies relying on such scaling (e.g., $[46,58])$ typically do not consider environmental conditions. This practice may be appropriate when the environment is fluctuating randomly and numbers are large (creating a random error in scaling). However, if the environmental change has a trend (e.g., due to climate change), indiscriminately using scaling could result in misleading conclusions; for example, should a population inhabit an area with stable temperature but 
declining food availability, the short term effects would be hard to detect because loggerhead turtles of a specific carapace length would still produce a corresponding number of eggs expected for that size (Figure 6, bottom left panel). Long-term effects might become visible decades later, as the size structure shifts towards smaller adults. Similarly, should temperature increase or decrease without a change in food availability, short term effects would show up as an increase or decrease in the reproduction output (number of eggs per nesting season, Figure 6, bottom right panel), even though the productivity of an area might not have been affected.

Our approach and results present a strong basis for future research. In addition to the scenarios of several constant temperatures and food densities tested in this study, temporary changes in temperature and/or food availability could be simulated. Loggerhead turtles are physiologically capable of withstanding prolonged periods of starvation [35], and compensatory growth has been observed [79] in sea turtles experiencing an increased food level after a period of decreased food availability. The consequences of the compensation on the energy budget later in life are unknown [65], and could be studied using the DEB model presented here (e.g., see [80]). Our model is (in principle) also capable of taking into account the effects of changes in food quality and gut residence time, should specific feeding and digestion data become available to justify the added complexity of the model. Frequency and length of the migrations can also be integrated into the model by modifying the energy budget in response to the distance traveled as suggested in $[23,36]$. The added realism of the actually experienced environment might give a more realistic size and maturation predictions, and also account for some of the observed intra-population variability in the growth rates, size and age at sexual maturity. The added complexity, however, would ideally rely on significantly richer data sets than currently available.

Effects of long-term changes in environmental factors, such as those resulting from climate change, could also be investigated using the model, which could be driven by climate change scenarios to assess the possible consequences (see Appendix B for an illustrative example). For example, an increase in sea surface temperature may be considered positive because it increases growth rate and reproduction output, but positive effects on the population depend on food availability: large decreases in food availability may negate any positive effects of a temperature increase. Similarly, reduction in food availability may be compensated by increase in temperature, but only up to a point. Environmental change could also have a synergistic 
effect: increase in both food availability and temperature would considerably increase both the growth rate and reproduction.

Quantifying the effects on the population level requires a population dynamics model. The developed DEB model can be directly nested into a population dynamics model using, for example, physiologically structured approach of De Roos and Persson [81], or individual-based approach of Martin et al. [82]. Subsequently, the coupled models could be employed to help the conservation efforts by, e.g., (re)evaluating the IUCN criteria [34] and the current assessment of the North Atlantic population (regional management units) as "low risk-high threat" [1].

\section{Acknowledgments}

Authors would like to thank Laure Pecquerie for generously sharing her "EVHR" Matlab scripts on the 2013 DEB workshop, with permission to use them. N.M, T.L, and T.K. have been supported by Croatian Science Foundation under the project 2202-ACCTA. M.J. was supported by the Research Grant Program of Inamori Foundation.

\section{Appendix A. Comparison of modeled and measured growth rates}

Several studies reporting growth rates of North Atlantic loggerhead turtles $[9,11,61,14]$ were used to obtain a set of values recorded in the field (Table A.2). We narrowed our literature search by focusing on studies reporting length as SCL (straight carapace length), and growth rates calculated from direct measurements rather than growth models or skeletochronology. Where length measurements and time intervals were reported in addition to growth rates (e.g., in Refs. [11,61]), raw data was used to calculate the growth rates and descriptive statistics (average, standard deviation, minimum, and maximum of the size class). Size classes were set as in Ref. [14] (30-39 cm, 40-49 cm etc.), and a growth rate was assigned to a specific size class based on the mean of the SCL at initial capture and SCL at recapture $[11,14]$.

Based on the size range represented in the studies (30-110 cm SCL), we randomly chose 3000 combinations of two carapace lengths that fall within the 30-110 cm range, and treated them as "length at capture" and "length at recapture". For the combinations that were less than $50 \mathrm{~cm}$ apart (largest 
length difference in the studies $[9,11,61,14])$, we simulated $15+15$ subsets of environments: 15 environments were set up with equidistant scaled food densities (15 values for scaled food density ranging from $0.25 \%$ to $300 \%$ of the current one), but with a single temperature (currently experienced by North Atlantic loggerhead turtles, $\left.T_{C}=294.95 \mathrm{~K}\right)$, and 15 environments were set up with equidistant temperatures (15 values ranging from $287.15 \mathrm{~K}$ to $303.15 \mathrm{~K}$ ), but with a single (current) scaled food density. Food availability $(f)$ and temperature correction were calculated using Equations 2 and 3, respectively (see Subsection 2.2 for details). In total, simulations were performed for 2664 combinations of carapace lengths. Because each combination had a set of values for environments differing in temperature and a set of values for environments differing in food availability, one combination of carapace lengths corresponded to roughly 30 individuals experiencing different environmental conditions. Size class was assigned based on the mean of the two lengths (as in Refs. [11,61]), and the descriptive statistics for all growth rates within a size class was then calculated (Table A.2).

The two subsets of simulated environments represent environments that are favorable for growth and reproduction of loggerhead turtles either due to temperature $\left(21.8^{\circ} \mathrm{C}\right)$ or due to food availability $(f=0.81)$ (or both). One would therefore expect that the range of predicted growth rates would include the growth rates recorded in nature. This was indeed the case for most size classes (Table A.2). Interestingly, within size classes for which more than two literature sources were available $(50-79 \mathrm{~cm})$, growth rates closer to the low end of the predicted range belonged to the samples which included or focused on loggerhead turtles inhabiting colder North Atlantic areas (north of Florida, [61, 14]), while growth rates close to the high end of the predicted range belonged to loggerhead turtles inhabiting warmer areas (south of Florida [9, 11]) with possibly also higher food availability.

Such a favorable agreement between model predictions and data obtained in the field corroborates the hypothesis of the strong causal relationship between the two environmental factors and biological properties of loggerhead turtles, as well as provides additional support to the validity of our mechanistic model and study setup.

\section{Appendix B. Implications for climate change}

Climate change might affect sea turtles at sea by changing the temperature and/or food availability in feeding and/or breeding areas [2, 39]. Here 
Table A.2: Growth rates obtained by model simulations (column 2) and growth rates reported in literature (columns 3-6). All growth rates are for straight line carapace length (SCL) and divided into 10-cm size classes by mean SCL [11, 14].

\begin{tabular}{|c|c|c|c|c|c|}
\hline \multirow{2}{*}{$\begin{array}{l}\text { Mean SCL } \\
\text { size class } \\
(\mathrm{cm})\end{array}$} & \multicolumn{5}{|c|}{ Growth rate $\left(\mathrm{cm}\right.$ year $\left.^{-1}\right)$} \\
\hline & $\begin{array}{l}\text { Simulation } \\
\text { (This study) }\end{array}$ & $\begin{array}{l}\text { Bjorndal } \\
\text { et al. [14] }\end{array}$ & $\begin{array}{l}\text { Snover et al. } \\
{[61]}\end{array}$ & $\begin{array}{l}\text { Bjorndal and } \\
\text { Bolten [11] }\end{array}$ & Mendonça $[9]$ \\
\hline $30-39$ & $\begin{array}{l}\mathbf{7 . 8 3} \pm \mathbf{2 . 5 9} \\
(1.26-15.96) \\
N=2250\end{array}$ & $\begin{array}{l}\mathbf{5 . 9 0} \\
(2.90 \& 8.90) \\
N=2\end{array}$ & - & - & - \\
\hline $40-49$ & $\begin{array}{l}\mathbf{6 . 4 9} \pm \mathbf{2 . 2 6} \\
(0.52-13.49) \\
N=5463\end{array}$ & - & - & $\begin{array}{l}\mathbf{1 5 . 6 7} \pm \mathbf{1 . 3 4} \\
(14.8117 .21) \\
N=3\end{array}$ & - \\
\hline $50-59$ & $\begin{array}{l}\mathbf{5 . 2 4} \pm \mathbf{1 . 8 8} \\
(0.19-11.07) \\
N=10904\end{array}$ & $\begin{array}{l}\mathbf{2 . 4 0} \pm \mathbf{2 . 5 0} \\
(-1.40-12.60) \\
N=47\end{array}$ & $\begin{array}{l}\mathbf{2 . 1 4} \pm \mathbf{0 . 7 9} \\
(1.26-2.76) \\
N=3\end{array}$ & - & $\begin{array}{l}7.40 \pm 1.40 \\
N=2\end{array}$ \\
\hline $60-69$ & $\begin{array}{l}\mathbf{3 . 9 9} \pm \mathbf{1 . 4 8} \\
(0.07-8.65) \\
N=14621\end{array}$ & $\begin{array}{l}\mathbf{1 . 5 0} \pm \mathbf{1 . 5 0} \\
(-0.80-8.80) \\
N=196\end{array}$ & $\begin{array}{l}\mathbf{2 . 6 8} \pm \mathbf{1 . 5 6} \\
(0.78-4.16) \\
N=6\end{array}$ & - & $\begin{array}{l}6.00 \pm \mathbf{2 . 3 0} \\
N=7\end{array}$ \\
\hline $70-79$ & $\begin{array}{l}\mathbf{2 . 8 3} \pm \mathbf{1 . 1 2} \\
(0.08-6.26) \\
N=13941\end{array}$ & $\begin{array}{l}\mathbf{1 . 1 0} \pm \mathbf{1 . 1 0} \\
(-0.50-5.80) \\
N=130\end{array}$ & $\begin{array}{l}\mathbf{2 . 1 5} \pm \mathbf{1 . 6 0} \\
(1.02-3.28) \\
N=2\end{array}$ & $\begin{array}{l}\mathbf{5 . 1 6} \\
(4.56 \& 5.77) \\
N=2\end{array}$ & $\begin{array}{l}\mathbf{5 . 0 0} \pm \mathbf{3 . 5 0} \\
N=4\end{array}$ \\
\hline $80-89$ & $\begin{array}{l}\mathbf{1 . 7 8} \pm \mathbf{0 . 8 1} \\
(0.07-3.82) \\
N=6732\end{array}$ & $\begin{array}{l}\mathbf{1 . 2 0} \pm \mathbf{1 . 4 0} \\
(-0.70-2.50) \\
N=129\end{array}$ & - & - & -4 \\
\hline $90-99$ & $\begin{array}{l}\mathbf{1 . 1 4} \pm \mathbf{0 . 5 9} \\
(0.03-2.34) \\
N=1273\end{array}$ & $\begin{array}{l}\mathbf{0 . 2 0} \pm \mathbf{0 . 5 0} \\
(-0.80-2.20) \\
N=41\end{array}$ & - & - & - \\
\hline $100-109$ & $\begin{array}{l}\mathbf{0 . 5 8} \pm \mathbf{0 . 2 1} \\
(0.16-0.99) \\
N=66\end{array}$ & $\begin{array}{l}\mathbf{0 . 2 0} \pm \mathbf{0 . 1 0} \\
(0.10-0.30) \\
N=3\end{array}$ & - & - & - \\
\hline
\end{tabular}




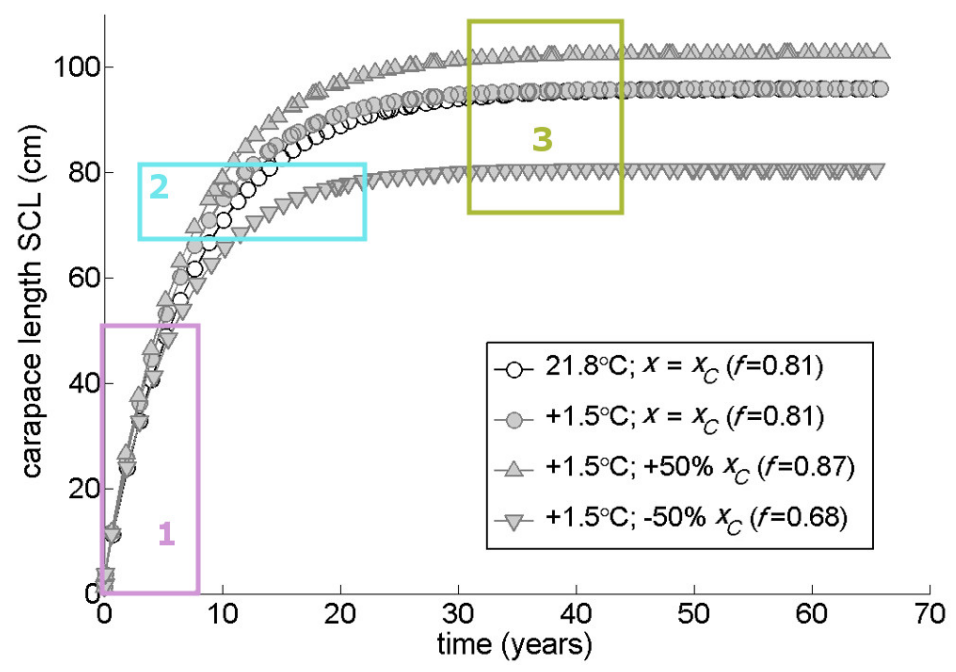

Figure B.7: Simulating possible scenarios resulting from climate change. Environmental factors were assumed to change relative to the current ones: an increase of temperature alone by $1.5^{\circ} \mathrm{C}$ from $21.8^{\circ} \mathrm{C}$ (scenario A) and the same temperature increase accompanied with a $50 \%$ increase (scenario B) or decrease (scenario C) of scaled food density from the current value, $x_{C}$. Enumerated rectangles mark three situations useful for studying and conserving loggerhead turtles in the context of climate change - see text for details.

we present an analysis of three possible scenarios relative to the conditions assumed as current for North Atlantic loggerhead turtles, to illustrate how the results from this study may be used for conservation purposes and for studying the effects of climate change on loggerheads (and other sea turtles).

In all three scenarios, we assumed that the sea temperature increased for $1.5^{\circ} \mathrm{C}[39,32]$. Scaled food density was assumed to remain the same (scenario A), increase by $50 \%$ (scenario B), or decrease by $50 \%$ (scenario C). Otherwise, identical setup as in the main text (see Section 2.1) was used to map the changes in the environment to the biological traits of loggerhead turtles. Conditions assumed as current comprised of temperature $T_{C}$ and scaled food density $x_{C}$ (see Section 2 for details).

The growth curves generated by the model (Figure B.7) under the temperature increase of $1.5^{\circ} \mathrm{C}$ imply that: (i) if food availability remains the same, there should be a visible effect on age-length curves, but no effect on the size range of individuals in a given population, and (ii) if food availability does change, the size range of individuals should also be affected. 
The said effects of increased temperature are not always easy to spot as illustrated by the enumerated rectangles in Figure B.7. In Rectangle 1, predicted growth curves are so close to each other that they all fall within the range of reported growth rates. Therefore, one cannot easily distinguish between the growth curve at the higher temperature and same food availability (scenario A) and the growth curve at higher temperature and higher food availability (scenario B). It is even harder to distinguish the growth curve under current environmental conditions from the one at higher temperature and lower food availability (scenario C), thus indicating that an increase in temperature can, up to a point, mask a decrease in food availability.

In Rectangle 2, changes in food availability and temperature have a synergistic effect on growth. Given the model predictions that loggerhead turtles reach puberty at around 76-78 cm SCL (see Subsection 3.1), age at puberty strongly varies between scenarios, ranging from around 9 years to more than 18 years. Age at puberty is a trait with an important role in population dynamics wherein the differences this big may separate prosperous from declining populations.

In Rectangle 3, as individuals approach their ultimate size, the effects of temperature on growth and size of individuals diminish. By contrast, food availability has a pronounced effect, suggesting that, e.g., longitudinal datasets of adult size distributions within a population may contain information on changes in food availability in an area. 


\section{Appendix C. Additional results on life-history traits}

Table C.3: Model predictions for a subset of 15 environments differing in food availability; temperature fixed at $21.8^{\circ} \mathrm{C}$ (vertical lines in Figure 3). Food availability, modeled using the scaled functional response $(f)$, was calculated for each environment via scaled food density ( $x$, Equation 2), which was obtained by modifying the current scaled food density $\left(x_{C}\right)$ by a factor given in column one (e.g., a factor of 3 means a $200 \%$ larger scaled food density, and a factor of 0.25 means $75 \%$ lower scaled food density compared to the current one). The corresponding scaled functional response is given in column two, and the selected life history traits in the following columns. Lengths are straight carapace lengths (SCL); mass refers to body mass. Reproduction output is expressed as number of eggs $(\#)$. Due to a relatively high $f_{C}$ and the saturating relationship between $x$ and $f$ (Eq. 2, Figure 2.2), food density, e.g., $50 \%$ lower than $x_{C}$ had a much stronger effect on the traits than food density $50 \%$ higher than $x_{C}$. Results for $x_{C}(f=0.81)$ are indicated in bold.

\begin{tabular}{lllllllll}
\hline $\begin{array}{l}\text { Factor } \\
\text { for } x_{C}\end{array}$ & $f(-)$ & $\begin{array}{l}\text { Age } \\
\text { puberty } \\
(\mathrm{yr})\end{array}$ & $\begin{array}{l}\text { Length } \\
\text { puberty } \\
(\mathrm{cm})\end{array}$ & $\begin{array}{l}\text { Mass } \\
\text { puberty } \\
(\mathrm{kg})\end{array}$ & $\begin{array}{l}\text { Length } \\
\text { ultimate } \\
(\mathrm{cm})\end{array}$ & $\begin{array}{l}\text { Mass } \\
\text { ultimate } \\
(\mathrm{kg})\end{array}$ & $\begin{array}{l}\text { Reprod. } \\
\text { seasonal } \\
(\#)\end{array}$ & $\begin{array}{l}\text { Reprod. } \\
\text { cumul. } \\
(\#)\end{array}$ \\
\hline \hline 3 & 0.927 & 9.72 & 76.48 & 71.93 & 109.75 & 258.39 & 1244 & 28497 \\
2.71 & 0.920 & 9.83 & 76.49 & 71.62 & 108.92 & 250.99 & 1201 & 27483 \\
2.43 & 0.912 & 9.97 & 76.51 & 71.24 & 107.91 & 242.20 & 1150 & 26270 \\
2.14 & 0.901 & 10.16 & 76.54 & 70.77 & 106.66 & 231.59 & 1087 & 24795 \\
1.86 & 0.888 & 10.41 & 76.57 & 70.18 & 105.07 & 218.52 & 1010 & 22965 \\
1.57 & 0.870 & 10.77 & 76.61 & 69.40 & 102.97 & 202.07 & 911 & 20636 \\
1.29 & 0.846 & 11.33 & 76.67 & 68.33 & 100.09 & 180.79 & 782 & 17581 \\
$\mathbf{1}$ & $\mathbf{0 . 8 1 0}$ & $\mathbf{1 2 . 3 4}$ & $\mathbf{7 6 . 7 7}$ & $\mathbf{6 6 . 7 7}$ & $\mathbf{9 5 . 8 7}$ & $\mathbf{1 5 2 . 3 4}$ & $\mathbf{6 0 6}$ & $\mathbf{1 3 4 1 9}$ \\
0.89 & 0.792 & 12.97 & 76.82 & 65.99 & 93.73 & 139.10 & 523 & 11454 \\
0.79 & 0.770 & 13.88 & 76.89 & 65.05 & 91.15 & 124.07 & 427 & 9203 \\
0.68 & 0.743 & 15.34 & 76.98 & 63.89 & 87.96 & 106.93 & 316 & 6617 \\
0.57 & 0.709 & 18.17 & 77.10 & 62.44 & 83.92 & 87.35 & 186 & 3669 \\
0.46 & 0.664 & 28.71 & 77.28 & 60.57 & 78.64 & 65.08 & 34 & 509 \\
0.36 & 0.604 & - & - & - & 71.44 & 45.37 & 0 & 0 \\
0.25 & 0.516 & - & - & - & 61.07 & 26.09 & 0 & 0 \\
\hline \hline
\end{tabular}


Table C.4: Model predictions for a subset of 15 environments differing in temperature; food availability fixed at $f_{C}=0.81$ (horizontal lines in Figure 3). Temperatures are expressed in degrees Celsius. Lengths are straight carapace lengths (SCL); mass refers to body mass. Reproduction output is expressed as number of eggs (\#). Results for $21.8^{\circ} \mathrm{C}$ $\left(T_{C}=294.95 \mathrm{~K}\right)$ are indicated in bold. Temperature had no predictable effect on length $(76.9 \mathrm{~cm} \mathrm{SCL})$ and body mass $(66.8 \mathrm{~kg})$ at puberty, therefore the two traits were omitted from the table.

\begin{tabular}{llllll}
\hline $\begin{array}{l}\text { Tempera- } \\
\text { ture }\left({ }^{\circ} \mathrm{C}\right)\end{array}$ & $\begin{array}{l}\text { Age } \\
\text { puberty } \\
(\mathrm{yr})\end{array}$ & $\begin{array}{l}\text { Length } \\
\text { ultimate } \\
(\mathrm{cm})\end{array}$ & $\begin{array}{l}\text { Mass } \\
\text { ultimate } \\
(\mathrm{kg})\end{array}$ & $\begin{array}{l}\text { Reprod. } \\
\text { seasonal } \\
(\#)\end{array}$ & $\begin{array}{l}\text { Reprod. } \\
\text { cumul. } \\
(\#)\end{array}$ \\
\hline \hline 30.00 & 6.49 & 95.89 & 172.63 & 1154 & 30922 \\
28.83 & 7.10 & 95.89 & 168.99 & 1055 & 27755 \\
27.66 & 7.77 & 95.89 & 165.63 & 964 & 24839 \\
26.49 & 8.51 & 95.88 & 162.53 & 880 & 22154 \\
25.31 & 9.33 & 95.88 & 159.68 & 803 & 19685 \\
24.14 & 10.23 & 95.88 & 157.05 & 732 & 17415 \\
22.97 & 11.23 & 95.88 & 154.62 & 666 & 15331 \\
$\mathbf{2 1 . 8 0}$ & $\mathbf{1 2 . 3 4}$ & $\mathbf{9 5 . 8 7}$ & $\mathbf{1 5 2 . 3 4}$ & $\mathbf{6 0 6}$ & $\mathbf{1 3 4 1 9}$ \\
20.69 & 13.50 & 95.84 & 150.30 & 553 & 11750 \\
19.57 & 14.78 & 95.80 & 148.33 & 503 & 10215 \\
18.46 & 16.20 & 95.74 & 146.37 & 457 & 8809 \\
17.34 & 17.75 & 95.62 & 144.32 & 414 & 7527 \\
16.23 & 19.49 & 95.44 & 142.10 & 373 & 6354 \\
15.11 & 21.40 & 95.17 & 139.58 & 333 & 5295 \\
14.00 & 23.52 & 94.78 & 136.65 & 295 & 4343 \\
\hline \hline
\end{tabular}

[1] B. P. Wallace, A. D. DiMatteo, A. B. Bolten, M. Y. Chaloupka, B. J. Hutchinson, F. A. Abreu-Grobois, J. A. Mortimer, J. A. Seminoff, D. Amorocho, K. A. Bjorndal, J. Bourjea, B. W. Bowen, R. B. Duenas, B. C. Choudhury, A. Costa, P. H. Dutton, A. Fallabrino, P. Casale, M. Girondot, M. Hamann, B. J. Hurley, E. M. Finkbeiner, A. Girard, M. Lopez-Mendilaharsu, M. A. Marcovaldi, J. A. Musick, R. Nel, N. J. Pilcher, S. Troeng, B. Witherington, R. B. Mast, Global conservation priorities for marine turtle, PLoS ONE 6 (2011) e24510.

[2] M. Chaloupka, N. Kamezaki, C. Limpus, Is climate change affecting the population dynamics of the endangered pacific loggerhead sea turtle?, Journal of Experimental Marine Biology and Ecology 356 (2008) 136143. 

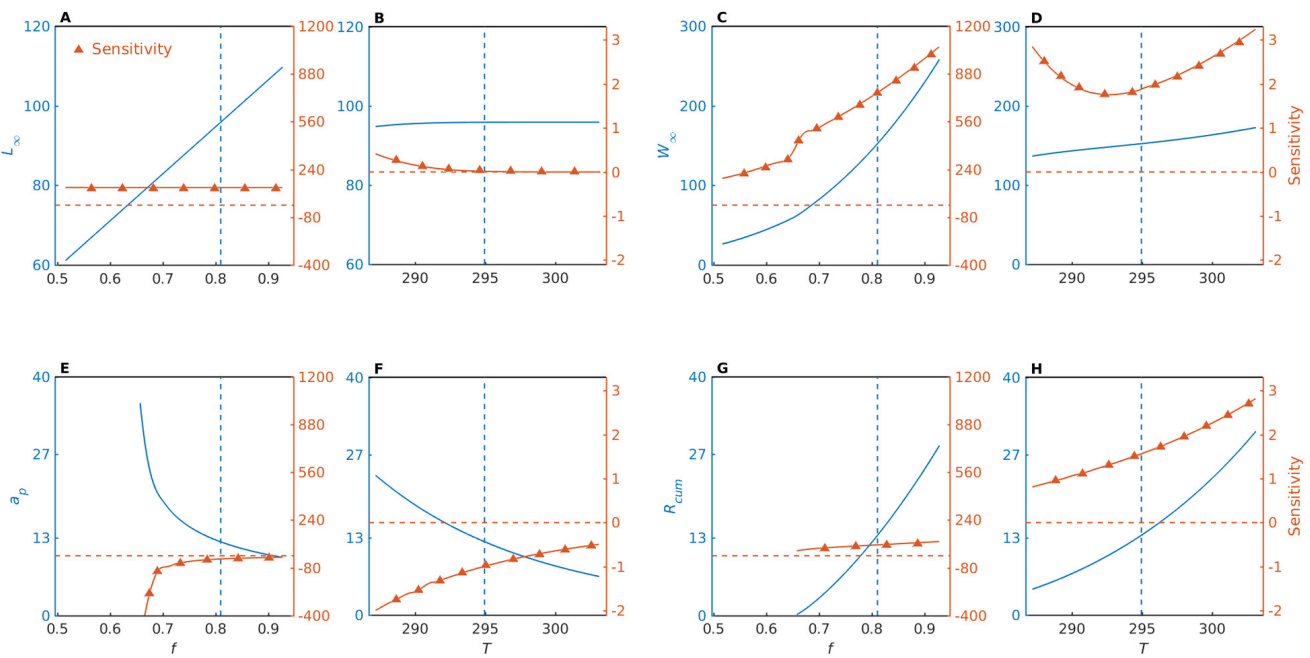

Figure C.8: Sensitivity analysis showing the change of a life history trait given a small change in the forcing variable ( $f$ or $T$ ). The horizontal dashed line marks zero sensitivity, i.e., where life-history traits are independent of the forcing variable. If sensitivity is a nonzero constant, then life-history traits depend on the forcing variable, but the relationship is linear.

[3] L. A. Hawkes, A. C. Broderick, M. H. Godfrey, B. J. Godley, Climate change and marine turtles, Endang Species Res 7 (2009) 137-154.

[4] A. Robinson, H. Crick, J. Learmonth, I. Maclean, C. Thomas, F. Bairlein, M. Forchhammer, C. Francis, J. Gill, B. Godley, J. Harwood, G. Hays, B. Huntley, A. Hutson, G. Pierce, M. Rehfisch, D. Sims, M. Vieira dos Santos, T. Sparks, D. Stroud, M. Visser, Travelling through a warming world: climate change and migratory species, Endangered Species Research 7 (2009) 87 - 99.

[5] M. J. Witt, L. A. Hawkes, M. H. Godfrey, B. J. Godley, A. C. Broderick, Predicting the impacts of climate change on a globally distributed species: The case of the loggerhead turtle, The Journal of Experimental Biology 213 (2010) 901-911.

[6] M. Salmon, J. Scholl, Allometric growth in juvenile marine turtles: possible role as an antipredator adaptation, Zoology 117 (2014) 131 138. 
[7] L. Stokes, J. Wyneken, L. B. Crowder, J. Marsh, The influence of temporal and spatial origin on size and early growth rates in captive loggerhead sea turtles (Caretta caretta) in the United States, Herpetological Conservation and Biology 1 (2006) 71-80.

[8] J. Braun-McNeill, S. P. Epperly, L. Avens, M. L. Snover, J. C. Taylor, Growth rates of loggerhead sea turtles (Caretta caretta) from the western North Atlantic, Herpetological Conservation and Biology 3 (2008) 273281.

[9] M. T. Mendonça, Comparative growth rates of wild immature Chelonia mydas and Caretta caretta in florida, Journal of Herpetology 15 (1981) 447-451.

[10] S. Piovano, M. Clusa, C. Carreras, C. Giacoma, M. Pascual, L. Cardona, Different growth rates between loggerhead sea turtles (Caretta caretta) of Mediterranean and Atlantic origin in the Mediterranean sea, Marine Biology 158 (2011) 2577-2587.

[11] K. A. Bjorndal, A. B. Bolten, Growth rates of juvenile loggerheads, Caretta caretta, in the Southern Bahamas, Journal of Herpetology 22 (1988) 480-482.

[12] K. A. Bjorndal, A. B. Bolten, H. R. Martins, Somatic growth model of juvenile loggerhead sea turtles Caretta caretta: Duration of pelagic stage, Marine Ecology Progress Series 202 (2000) 265-272.

[13] K. A. Bjorndal, A. B. Bolten, T. Dellinger, C. Delgado, H. R. Martins, Compensatory growth in oceanic loggerhead sea turtles: Response to a stochastic environment, Ecology 84 (2003) 1237-1249.

[14] K. A. Bjorndal, B. A. Schroeder, A. M. Foley, B. E. Witherington, M. Bresette, D. Clark, R. M. Herren, M. D. Arendt, J. R. Schmid, A. B. Meylan, P. A. Meylan, J. A. Provancha, K. M. Hart, M. M. Lamont, R. R. Carthy, A. B. Bolten, Temporal, spatial, and body size effects on growth rates of loggerhead sea turtles (Caretta caretta) in the Northwest Atlantic, Marine Biology (2013) 1-10.

[15] B. J. Godley, J. M. Blumenthal, A. C. Broderick, M. S. Coyne, M. H. Godfrey, L. A. Hawkes, M. J. Wittp, Satellite tracking of sea turtles: 
Where have we been and where do we go next?, Endang Species Res 3 (2007) 1-20.

[16] M. Pajuelo, K. A. Bjorndal, K. J. Reich, H. B. V. Zanden, L. A. Hawkes, A. B. Bolten, Assignment of nesting loggerhead turtles to their foraging areas in the Northwest Atlantic using stable isotopes, Ecosphere 3 (2012) $1-18$.

[17] S. K. Pikesley, A. C. Broderick, D. Cejudo, M. S. Coyne, M. H. Godfrey, B. J. Godley, P. Lopez, L. F. Lopez-Jurado, S. E. Merino, N. Varo-Cruz, M. J. Witt, L. A. Hawkes, Modelling the niche for a marine vertebrate: a case study incorporating behavioural plasticity, proximate threats and climate change, Ecography 38 (2015) 803-812.

[18] M. L. Snover, Growth and ontogeny of sea turtles using skeletochronology: methods, validation and application to conservation, Ph.D. thesis, Duke University, 2002.

[19] S. H. Peckham, D. Maldonado-Diaz, Y. Tremblay, R. Ochoa, J. Polovina, G. Balazs, P. H. Dutton, W. J. Nichols, Demographic implications of alternative foraging strategies in juvenile loggerhead turtles Caretta caretta of the North Pacific Ocean, Mar Ecol Prog Ser 425 (2011) 269280.

[20] M. Koot, Elements of Mathematical Ecology, Cambridge University Press, 2001.

[21] J. B. Iverson, Correlates of reproductive output in turtles (order Testudines), Herpetological Monographs 6 (1992) 25-42.

[22] L. A. Hawkes, A. C. Broderick, M. S. Coyne, M. H. Godfrey, L.-F. LopezJurado, P. Lopez-Suarez, S. E. Merino, N. Varo-Cruz, B. J. Godley, Phenotypically linked dichotomy in sea turtle foraging requires multiple conservation approaches, Current Biology 16 (2006) 990-995.

[23] H. Hatase, K. Tsukamoto, Smaller longer, larger shorter: energy budget calculations explain intrapopulation variation in remigration intervals for loggerhead sea turtles ( Caretta caretta), Canadian Journal of Zoology 86 (2008) 595-600. 
[24] S. Vieira, S. Martins, L. Hawkes, A. Marco, M. Teodosio, Biochemical indices and life traits of loggerhead turtles (Caretta caretta) from Cape Verde islands, PLoS ONE 9 (2014) e112181.

[25] A. R. Solow, K. A. Bjorndal, A. B. Bolten, Annual variation in nesting numbers of marine turtles: the effect of sea surface temperature on remigration intervals, Ecology Letters 5 (2002) 742-746.

[26] K. Sato, Y. Matsuzawa, H. Tanaka, T. Bando, S. Minamikawa, W. Sakamoto, Y. Naito, Internesting intervals for loggerhead turtles, Caretta caretta, and green turtles, Chelonia mydas, are affected by temperature, Canadian Journal of Zoology 76 (1998) 1651-1662.

[27] G. Hays, A. Broderick, F. Glen, B. Godley, J. Houghton, J. Metcalfe, Water temperature and internesting intervals for loggerhead (Caretta caretta) and green (Chelonia mydas) sea turtles, Journal of Thermal Biology 27 (2002) $429-432$.

[28] A. D. Mazaris, A. S. Kallimanis, S. P. Sgardelis, J. D. Pantis, Do longterm changes in sea surface temperature at the breeding areas affect the breeding dates and reproduction performance of Mediterranean loggerhead turtles? implications for climate change, Journal of Experimental Marine Biology and Ecology 367 (2008) 219-226.

[29] V. S. Saba, P. Santidrin-Tomillo, R. D. Reina, J. R. Spotila, J. A. Musick, D. A. Evans, F. V. Paladino, The effect of the El Niño Southern Oscillation on the reproductive frequency of eastern Pacific leatherback turtles, Journal of Applied Ecology 44 (2007) 395-404.

[30] R. D. Reina, J. R. Spotila, F. V. Paladino, A. E. Dunham, Changed reproductive schedule of eastern Pacific leatherback turtles Dermochelys coriacea following the 1997-98 El Niño to La Niña transition, Endang Species Res 7 (2009) 155-161.

[31] K. S. V. Houtan, J. M. Halle, Long-term climate forcing in loggerhead sea turtle nesting, PLoS ONE 6 (2011) e19043.

[32] NOAA, Sea surface temperatures reach highest level in 150 years on northeast continental shelf, public release, 2013. Contact: Shelley Dawicki. 
[33] L. Hawkes, A. Broderick, M. Godfrey, B. Godley, Investigating the potential impacts of climate change on a marine turtle population, Global Change Biology 13 (2007) 923-932.

[34] D. A. Keith, M. Mahony, H. Hines, J. Elith, T. J. Regan, J. B. Baumgartner, D. Hunter, G. W. Heard, N. J. Mitchell, K. M. Parris, et al., Detecting extinction risk from climate change by IUCN Red List criteria, Conservation biology 28 (2014) 810-819.

[35] N. Marn, S. Kooijman, M. Jusup, T. Legović, T. Klanjšček, Inferring physiological energetics of loggerhead turtle (Caretta caretta) from existing data using a general metabolic theory, Marine Environmental Research 126 (2017) 14-25.

[36] S. A. L. M. Kooijman, Dynamic Energy Budget theory for metabolic organisation, Cambridge University Press, 2010.

[37] Add_my_pet: species list, www.bio.vu.nl/thb/deb/deblab/add_my_pet/index.html, N/A. Curators: Kooijman, S A L M; Lika, K ; Marques, G; Augustine, S; Pecquerie, L; Accessed: 15-Aug-2016.

[38] M. E. Hedges, Development and application of a multistate model to the northern subpopulation of loggerhead sea turtles (Caretta caretta), Masters thesis, Ph.D. thesis, Virginia Polytechnic Institute and State University, 2007.

[39] L. A. Hawkes, A. C. Broderick, M. S. Coyne, M. H. Godfrey, B. J. Godley, Only some like it hot - quantifying the environmental niche of the loggerhead sea turtle, Diversity and Distributions 13 (2007) 447-457.

[40] R. Nisbet, E. Muller, K. Lika, S. Kooijman, From molecules to ecosystems through Dynamic Energy Budget models, J. Anim. Ecol. 69 (2000) 913-926.

[41] S. Kooijman, Quantitative aspects of metabolic organization: a discussion of concepts, Philosophical Transactions of the Royal Society of London B: Biological Sciences 356 (2001) 331-349.

[42] T. Sousa, T. Domingos, S. A. L. M. Kooijman, From empirical patterns to theory: A formal metabolic theory of life, Phil. Trans. R. Soc. B 363 (2008) 2453-2464. 
[43] T. Sousa, T. Domingos, J.-C. Poggiale, S. A. L. M. Kooijman, Dynamic Energy Budget theory restores coherence in biology, Phil. Trans. R. Soc. B 365 (2010) 3413-3428.

[44] R. M. Nisbet, M. Jusup, T. Klanjscek, L. Pecquerie, Integrating Dynamic Energy Budget (DEB) theory with traditional bioenergetic models, J. Exp. Biol. 215 (2012) 892-902.

[45] M. Jusup, T. Sousa, T. Domingos, V. Labinac, N. Marn, Z. Wang, T. Klanjšček, Physics of metabolic organization, Physics of Life Reviews 20 (2017) $1-39$.

[46] M. Tiwari, K. A. Bjorndal, Variation in morphology and reproduction in loggerheads, Caretta caretta, nesting in the United States, Brazil, and Greece, Herpetologica 56 (2000) 343-356.

[47] G. C. Hays, J. R. Speakman, Reproductive investment and optimum clutch size of loggerhead sea turtles (Caretta caretta), Journal of Animal Ecology 60 (1991) 455-462.

[48] K. Lika, M. R. Kearney, V. Freitas, H. W. van der Veer, J. van der Meer, J. W. Wijsman, L. Pecquerie, S. A. Kooijman, The covariation method for estimating the parameters of the standard Dynamic Energy Budget model I: Philosophy and approach, Journal of Sea Research 66 (2011) $270-277$.

[49] T. Jager, B. T. Martin, E. I. Zimmer, DEBkiss or the quest for the simplest generic model of animal life history, Journal of Theoretical Biology (2013).

[50] R. M. Nisbet, B. T. Martin, A. M. de Roos, Integrating ecological insight derived from individual-based simulations and physiologically structured population models, Ecological Modelling 326 (2016) 101-112.

[51] M. Jusup, T. Klanjšček, H. Matsuda, Simple measurements reveal the feeding history, the onset of reproduction, and energy conversion efficiencies in captive bluefin tuna, Journal of Sea Research 94 (2014) $144-155$.

[52] S. A. Kooijman, Comments on dynamic energy budget theory for metabolic organisation [www document, updated ocassionally], 
2015. http://www.bio.vu.nl/thb/research/bib/Kooy2010_c.pdf, Accessed: 30/11/2015.

[53] M. A. Read, G. C. Grigg, C. J. Limpus, Body temperatures and winter feeding in immature green turtles, Chelonia mydas, in Moreton Bay, Southeastern Queensland, Journal of Herpetology 30 (1996) 262 - 265.

[54] L. A. Hawkes, M. J. Witt, A. C. Broderick, J. W. Coker, M. S. Coyne, M. Dodd, M. G. Frick, M. H. Godfrey, D. B. Griffin, S. R. Murphy, T. M. Murphy, K. L. Williams, B. J. Godley, Home on the range: spatial ecology of loggerhead turtles in Atlantic waters of the USA, Diversity and Distributions 17 (2011) 624-640.

[55] S. Hochscheid, C. R. McMahon, C. J. Bradshaw, F. Maffucci, F. Bentivegna, G. C. Hays, Allometric scaling of lung volume and its consequences for marine turtle diving performance, Comparative Biochemistry and Physiology Part A: Molecular \& Integrative Physiology 148 (2007) $360-367$.

[56] Georgia sea turtle centre- frequently asked questions, http://gstc.jekyllisland.com/, N/A. Accessed: 18-Nov-2015.

[57] A. Bolten, B. Witherington (Eds.), Loggerhead Sea Turtles, Smithsonian Books, Washington D.C., 2003.

[58] C. Wabnitz, D. Pauly, Length-weight relationships and additional growth parameters for sea turtles, in: M. L. D. Palomares, D. Pauly (Eds.), Von Bertalanffy growth parameters of non-fish marine organisms, 2008, p. 138. Fisheries centre research report 16(10).

[59] A. Zenetos, O. Siokou-Frangou, I.and Gotsis-Skretas, S. Groom, Europe's Biodiversity: biogeographical regions and seas, EEA., p. pp22.

[60] P. Casale, A. D. Mazaris, D. Freggi, C. Vallini, R. Argano, Growth rates and age at adult size of loggerhead sea turtles (Caretta caretta) in the Mediterranean sea, estimated through capture-mark-recapture records, Scientia Marina 73 (2009) 589-595.

[61] M. L. Snover, L. Avens, A. A. Hohn, Back-calculating length from skeletal growth marks in loggerhead sea turtles Caretta caretta, Endang Species Res 3 (2007) 95-104. 
[62] P. Casale, N. Conte, D. Freggi, C. Cioni, R. Argano, Age and growth determination by skeletochronology in loggerhead sea turtles (Caretta caretta) from the Mediterranean sea, Scientia Marina 75 (2011) 197203.

[63] P. Casale, A. Mazaris, D. Freggi, Estimation of age at maturity of loggerhead sea turtles Caretta caretta in the mediterranean using lengthfrequency data, Endangered Species Research 13 (2011) 123-129.

[64] T. Madsen, R. Shine, Silver spoon and snake body sizes: prey availability early in life influences long-term growth rates of free-ranging pythons, Journal of Animal Ecology 69 (2000) 952 - 958.

[65] N. B. Metcalfe, P. Monaghan, Compensation for a bad start: grow now, pay later?, Trends in Ecology \& Evolution 16 (2001) $254-260$.

[66] L. von Bertalanffy, The theory of open systems in physics and biology, Science 111 (1950) 23-29.

[67] L. Pecquerie, R. Fablet, H. de Pontual, S. Bonhommeau, M. AlunnoBruscia, P. Petitgas, S. A. Kooijman, Reconstructing individual food and growth histories from biogenic carbonates, MEPS 447 (2012) 151164 .

[68] N. B. Frazer, L. M. Ehrhart, Preliminary growth models for green, Chelonia mydas, and loggerhead, Caretta caretta, turtles inthe wild, Copeia (1985) 73-79. Cited in Bjorndal and Bolten (1988).

[69] A. D. Tucker, Nest site fidelity and clutch frequency of loggerhead turtles are better elucidated by satellite telemetry than by nocturnal tagging efforts: implications for stock estimation, Journal of Experimental Marine Biology and Ecology 383 (2010) 48-55.

[70] A. D. Mazaris, A. S. Kallimanis, J. Tzanopoulos, S. P. Sgardelis, J. D. Pantis, Sea surface temperature variations in core foraging grounds drive nesting trends and phenology of loggerhead turtles in the Mediterranean sea, Journal of Experimental Marine Biology and Ecology 379 (2009) $23-27$.

[71] C. J. Limpus, Puberty and first breeding in Caretta caretta, in: T. H. Richardson, J. I. Richardson, M. Donnelly (Eds.), Proceedings of the 
10th annual workshop on sea turtle biology and conservation, pp. 8184. NOAA Technical Memorandum NMFS-SEFSC - 278.

[72] G. Blanvillain, D. W. Owens, G. Kuchling, Hormones and reproductive cycles in turtles, in: Hormones and Reproduction of Vertebrates, volume 3 - Reptiles, Elsevier Inc, 2011.

[73] R. Scott, R. Marsh, G. C. Hays, Life in the really slow lane: loggerhead sea turtles mature late relative to other reptiles, Functional Ecology 26 (2012) 227-235.

[74] A. C. Broderick, F. Glen, B. J. Godley, G. C. Hays, Variation in reproductive output of marine turtles, Journal of Experimental Marine Biology and Ecology 288 (2003) 95-109.

[75] S. L. Deem, T. M. Norton, M. Mitchell, A. Segars, A. R. Alleman, C. Cray, R. H. Poppenga, M. Dodd, W. B. Karesh, Comparison of blood values in foraging, nesting, and stranded loggerhead turtles (Caretta caretta) along the coast of Georgia, Journal of Wildlife Diseases 45 (2009) 41-56.

[76] L. Hawkes, A. Broderick, M. Godfrey, B. Godley, Status of nesting loggerhead turtles Caretta caretta at Bald Head island (North Carolina, USA) after 24 years of intensive monitoring and conservation., Oryx 39 (2005) 65-72.

[77] D. Margaritoulis, R. Argano, I. Baran, F. Bentivegna, M. Bradai, J. Caminas, P. Casale, G. D. Metrio, A. Demetropoulos, G. Gerosa, B. Godley, D. Haddoud, J. Houghton, L. Laurent, B. Lazar, Loggerhead turtles in the Mediterranean Sea: Present knowledge and conservation perspectives, in: [57], pp. 175-198.

[78] J. Miller, C. Limpus, M. Godfrey, Nest site selection, oviposition, eggs, development, hatching, and emergence of loggerhead sea turtles, in: A. Bolten, B. Witherington (Eds.), Ecology and Conservation of Loggerhead Sea Turtles, University Press of Florida, Gainesville, Florida, 2003, pp. 125-143.

[79] A. M. Roark, K. A. Bjorndal, A. Bolten, Compensatory responses to food restriction in juvenile green turtles (Chelonia mydas), Ecology 90 (2009) 2524-2534. 
1180

1181

1182

1183

1184

1185

1186

1187

[80] L. Bavčević, T. Klanjšček, V. Karamarko, I. Aničić, T. Legović, Compensatory growth in gilthead sea bream (Sparus aurata) compensates weight, but not length, Aquaculture 301 (2010) 57 - 63 .

[81] A. M. De Roos, L. Persson, Physiologically structured models-from versatile technique to ecological theory, Oikos 94 (2001) 51-71.

[82] B. T. Martin, E. I. Zimmer, V. Grimm, T. Jager, Dynamic Energy Budget theory meets individual-based modelling: a generic and accessible implementation, Methods in Ecology and Evolution 3 (2012) 445-449. 